\title{
Numerical Analysis of Damaged River Embankment during the 2011 Tohoku Earthquake Using a Multiphase-Coupled FEM Analysis Method
}

\author{
Li Chen and Sayuri Kimoto \\ Department of Civil and Earth Resources Engineering, Kyoto University, Kyoto 615-8540, Japan \\ Correspondence should be addressed to Sayuri Kimoto; kimoto.sayuri.6u@kyoto-u.ac.jp
}

Received 19 April 2018; Accepted 5 June 2018; Published 30 July 2018

Academic Editor: Ching Hung

Copyright (c) $2018 \mathrm{Li}$ Chen and Sayuri Kimoto. This is an open access article distributed under the Creative Commons Attribution License, which permits unrestricted use, distribution, and reproduction in any medium, provided the original work is properly cited.

\begin{abstract}
According to the investigation and restoration report by the Ministry of Land, Infrastructure, Transport and Tourism (MLIT, 2011), 1195 river embankments were damaged in Tohoku region during the 2011 Tohoku earthquake. The failures of the river embankments were typically due to the soil liquefaction of embankment fill. In the present study, a severely damaged river embankment along Naruse River was simulated by using a three-phase coupled finite element program, namely, COMVI2DDY, which is developed to analyze large deformation behavior of partially saturated soils. In addition, the reconsolidation process after the earthquake was simulated. To reproduce the reconsolidation behavior, a cyclic elastoplastic constitutive model based on nonlinear kinematical hardening rule was modified by considering stiffness recovery during reconsolidation. From the analysis results, it could be concluded that the numerical method is able to reproduce the key characteristics of the actual damaged pattern; the embankment is heavily damaged and deformed largely towards the land side, and the settlement at the top of the embankment is $2.5 \mathrm{~m}$. In addition, realistic simulation results can be obtained from the reconsolidation analysis.
\end{abstract}

\section{Introduction}

A river embankment is a large-scale earth structure that mainly functions as a measure for flood prevention. Though the geological stratigraphy of the river embankment varies from location to location, a particular common feature is that the ground water table within the embankment is very shallow, hence keeping the earth embankment close to full saturation. Such feature will make the embankments susceptible to soil liquefaction, especially for those which are filled with granular soils.

In Japan, the seismic performance of the river embankment has been inspected in the last decades [1] since the significant subsidence of the Yodo River levee in Osaka was reported by the 1995 Kobe earthquake. The vulnerability of numerous river embankments, however, remains unknown until the occurrence of embankment failure due to soil liquefaction induced by large earthquakes. For instance, more than 2000 river embankments were damaged during the 2011 off-the-Pacific-Coast Tohoku earthquake. According to the investigation and restoration report by the Ministry of Land, Infrastructure, Transport and Tourism [2], 1195 river embankments were damaged in the Tohoku region with the total length of approximately 100,000 meters. Liquefaction of river embankments and the failure mechanism during the 2011 Tohoku earthquake were discussed and summarized by some researchers (e.g., [1, 3-5]). The failures of the river embankments were mainly due to the soil liquefaction of foundation soil or embankment fill. Figures 1 and 2 show heavily damaged embankments during the earthquake.

In order to prevent future losses, it is necessary to understand the failure mechanism of river embankments due to soil liquefaction. On the other hand, the restoration 


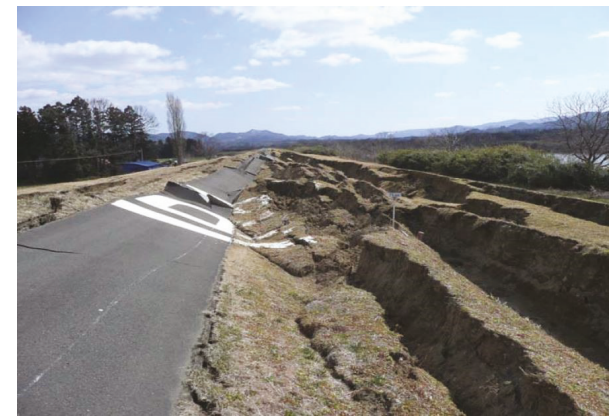

Figure 1: Damaged river embankment in the Edano area of Abukuma River [2].

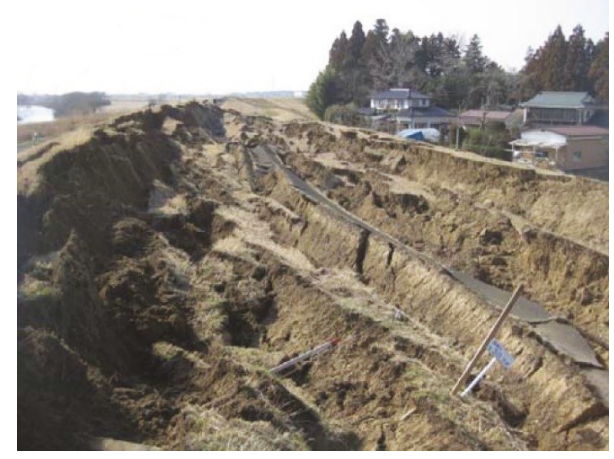

Figure 2: Damaged river embankment at Shimonakanome upper stream of Naruse River [2].

time for damaged river embankments is usually limited, as they are to be reinstated before the raining reason. It is hence common that the embankment was repaired without the knowledge of its stress status or hydraulic characteristics. This would result in potential risk of damage in the future. Hence, a reconsolidation mechanism after liquefaction is as important as a soil liquefaction mechanism for a river embankment.

Over the past few decades, multiphase coupled numerical analysis methods have been proposed for partially saturated soils (e.g., $[6,7])$. Numerical simulations of embankment liquefaction have been conducted using various modelling methods in conjunction with a variety of constitutive models. Some (e.g., [8-10]) adopted infinitesimal strain theory to simulate seismic response of embankments. The infinitesimal strain theory is capable of capturing some important characteristics of soil liquefaction at the element level, such as the increase in pore water pressure and the loss of effective stress, but can hardly replicate the embankment deformation pattern, especially under the extreme ground motion. In addition, the behavior of partially saturated soil is not considered in most, and the embankment fill is generally treated as a dry material. To analyze the soil behavior within the embankment, however, the descriptions of partially saturated soil, such as the soil-water characteristics and the constitutive model for unsaturated soil, need to be introduced. Recently, Yoshikawa et al. [11] conducted a numerical analysis on the seismic behavior of an unsaturated embankment focusing on the effect of the groundwater level. There are, however, few numerical examples to reproduce the actual damage of river embankment.

In the present study, the dynamic behavior of a severely damaged river embankment along Naruse River during the 2011 Tohoku earthquake was simulated by using a threephase coupled finite element program, namely, COMVI2DDY $[12,13]$. The program COMVI2D-DY was developed to analyze large deformation behavior of partially saturated soils under dynamic loading. The simulations are compared with the observed deformation pattern of the river embankment. Failure mechanisms due to liquefaction of embankment fill including but not limited to the pore water pressure distribution and the effective stress distribution can be clarified. In addition, reconsolidation analysis was carried out as a continuation of the dynamic one to understand the mechanical as well as the hydraulic characteristics of the damaged embankment before restoration. To reproduce the reconsolidation behavior, a cyclic elastoplastic constitutive model based on the nonlinear kinematical hardening rule [14] was modified by considering stiffness recovery during reconsolidation, and the behavior is discussed.

\section{Governing Equations for Large Deformation Dynamic Analysis of Multiphase Geomaterials}

A finite element program, namely, COMVI2D-DY [13], was developed to simulate large deformation of partially saturated soil under dynamic loading. The governing equations of dynamic analysis for multiphase geomaterials, that is, air-water-soil three-phase materials, are described within the framework of theory of porous media. In the theory, the governing equations are described for the multiphase mixture, that is, an immiscible mixture of solid and fluids [15]. The $u-p$ formulation based on the updated Lagrangian method has been employed along with the Jaumann rate of Cauchy stress tensor for the weak form of the equilibrium equation.

An elastoplastic constitutive model $[14,16]$ is used to reproduce cyclic plastic behavior and liquefaction behavior, that is, the reduction of the mean effective stress of the saturated sandy soil. In the model, a nonassociativity parameter that controls the nonassociative behavior of sandy soils is incorporated. The formulation of the elastoplastic constitutive model is given in the following section. For the partially saturated sand, an extended elastoplastic model considering the effect of suction [17] is used, in which the so-called skeleton stress which provides a natural application of the two-phase mixture theory to the three-phase mixture (e.g., [18-21]) is the basic stress variable. In addition, the suction is included in the overconsolidation boundary surface and the yield surface to describe the bonding effect. An elastoviscoplastic constitutive model by Kimoto et al. [22] was used for clayey soils which can reproduce the dynamic behavior of clayey soils which exhibit plastic behavior as well as the rate-dependent behaviors. A van Genuchten-type model [23] is used as a soil-water characteristic curve. 
The weak form of the continuity equation for water and gas, the conservation of momentum for the whole mixture is discretized in space by the finite element method. Assuming two-dimensional plane strain condition, an 8-node isoparametric element is used for the displacement, velocity, and acceleration of the solid skeleton, and a 4-node isoparametric element is used for pore water pressure and pore gas pressure. For the time discretization, Newmark's $\beta$ method is adopted. The detailed descriptions for the dynamic finite element formulations are shown by Shahbodagh Khan [13]. Note that the pore-air pressure is assumed to be zero in the following simulations since the effect of air pressure was found to be negligible under drained conditions at the surface boundary.

\section{Elastoplastic Constitutive Model}

3.1. Formulation of the Model. Oka and Kimoto $[14,16]$ have developed a cyclic elastoplastic constitutive model based on the kinematical hardening theory by extending the previous model by Oka et al. [24]. In the new model, the yield function includes the changes in the stress ratio and the mean effective stress. A nonassociativity parameter that controls the nonassociative behavior of sandy soils, which is important for the simulation of unstable behavior such as liquefaction, is incorporated. In this section, the formulation of the model is briefly shown. The detailed explanations for the model are shown in Oka and Kimoto [14, 16].

The overconsolidation boundary which defines the boundary between the normally consolidated region and the overconsolidated region is given in

$$
f_{b}=\bar{\eta}_{\xi}^{*}+M_{m}^{*} \ln \left(\frac{\sigma_{m}^{\prime}}{\sigma_{m b}^{\prime}}\right)=0 .
$$

In this equation, $f_{b} \geq 0$ indicates a normally consolidated region, whereas $f_{b}<0$ indicates an overconsolidated region. Relative stress ratio $\bar{\eta}_{\xi}^{*}$ is given in

$$
\bar{\eta}_{\xi}^{*}=\left\{\left(\eta_{i j}^{*}-\xi_{i j}\right)\left(\eta_{i j}^{*}-\xi_{i j}\right)\right\}^{1 / 2}, \quad \eta_{i j}^{*}=\frac{s_{i j}}{\sigma_{m}^{\prime}},
$$

where $\sigma_{m}^{\prime}$ is the mean effective stress and $\eta_{i j}^{*}$ denotes the stress ratio tensor. The hardening parameter $\sigma_{m b}^{\prime}$ controls the size of the overconsolidation boundary surface. $M_{m}^{*}$ is the value of the stress ratio at the transformation phase, at which point, the soil transforms from compression to dilation. The initial value of $\xi_{i j}$ is equal to the stress ratio tensor after the end of consolidation, and $\xi_{i j}$ follows and evolutional equation as

$$
d \xi_{i j}=-C_{d} \xi_{i j} d \gamma^{p *}, \quad \gamma^{p *}=\int d \gamma^{p *}=\int\left(d e_{i j}^{P} d e_{i j}^{P}\right)^{1 / 2},
$$

where $\gamma^{p *}$ is the accumulated plastic shear strain from the initial state, $d e_{i j}^{P}$ is the plastic deviatoric strain increment, and $C_{d}$ is a material constant which controls the disappearance of anisotropy.

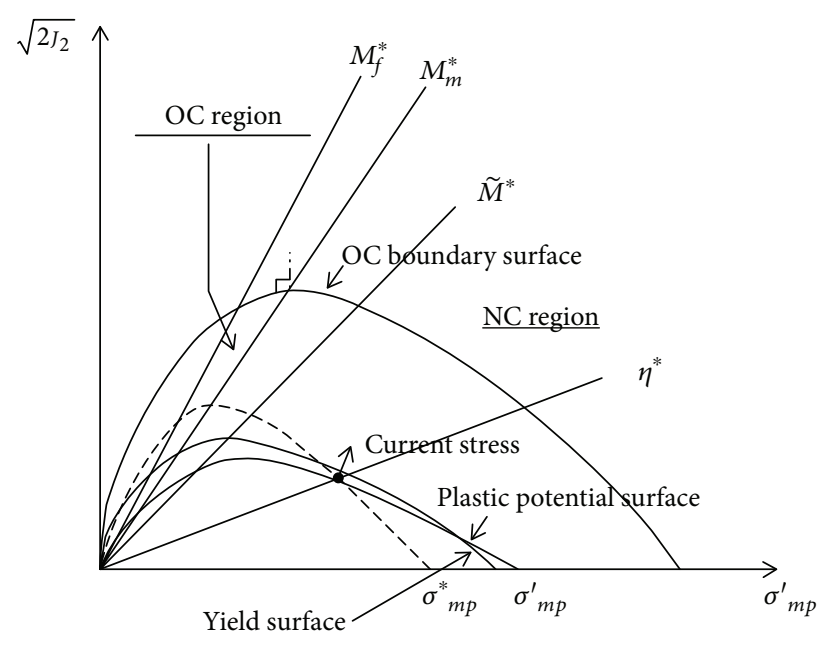

FIgURe 3: Overconsolidation boundary surface, yield function, and plastic potential function for an isotropically consolidated state.

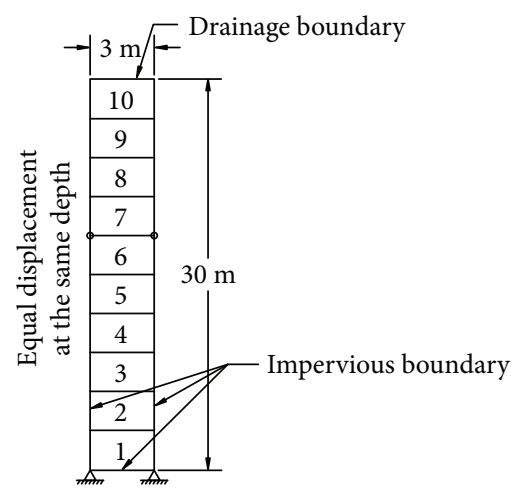

Figure 4: 1-D model for parametric study.

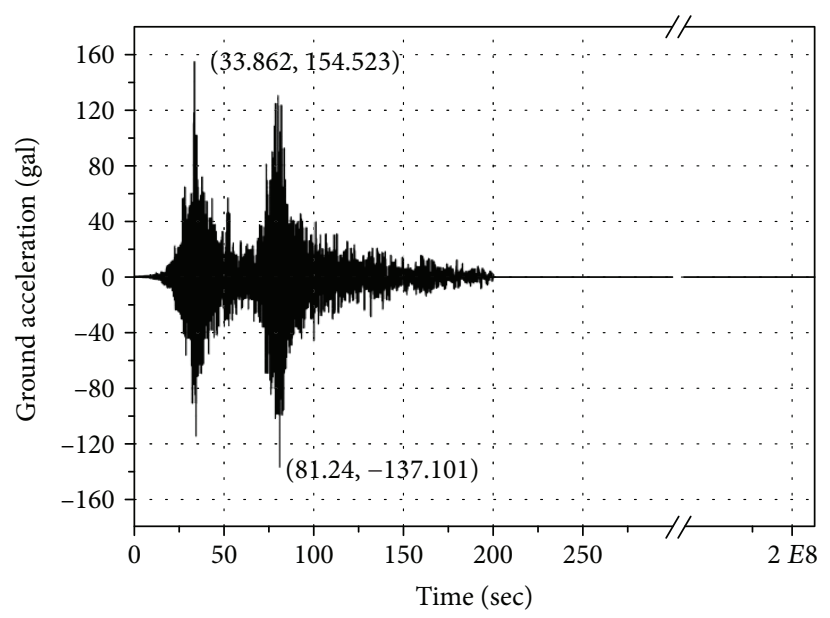

— MYGH06 at -80 m Tajiri station (NIED, 2011)

FIGURE 5: Ground acceleration input [25].

The static yield surface is given by a function of the nonlinear kinematic hardening rule of the stress ratio, mean effective stress, and plastic volumetric strain, in 


$$
\begin{aligned}
& f_{y}=\bar{\eta}_{\chi}^{*}+C_{n s} \tilde{M}^{*}\left(\ln \frac{\sigma_{m k}^{\prime}}{\sigma_{m a}^{\prime}}+\left|\ln \frac{\sigma_{m}^{\prime}}{\sigma_{m k}^{\prime}}-y_{m}^{*}\right|\right)=0, \\
& \bar{\eta}_{\chi}^{*}=\left\{\left(\eta_{i j}^{*}-\chi_{i j}^{*}\right)\left(\eta_{i j}^{*}-\chi_{i j}^{*}\right)\right\}^{1 / 2},
\end{aligned}
$$

where $\sigma_{m k}^{\prime}$ is in the unit of stress which is kilopascal $(\mathrm{kPa}) \cdot y_{m}^{*}$ is the kinematic hardening parameter that associates with the change of plastic volumetric strain. Parameter $C_{n s}$ is the nonassociativity material parameter which is ranging from zero to one; $C_{n s}=1.0$ for associated flow rule and $C_{n s}<1.0$ for nonassociated flow rule. It should be noted that $C_{n s}=1.0$ is assumed before the stress ratio reaches the phase transformation line and during consolidation after liquefaction. $\chi_{i j}^{*}$ is the back stress parameters with the same dimension as the stress ratio $\eta_{i j}^{*}$. The nonlinear hardening rule, as an evolutional equation of $\chi_{i j}^{*}$, is given by

$$
d \chi_{i j}^{*}=B^{*}\left(A^{*} d e_{i j}^{P}-\chi_{i j}^{*} d \gamma^{P *}\right)
$$

where $A^{*}$ and $B^{*}$ are material parameters related to the stress ratio at failure, $M_{f}^{*}$, and the nondimensional initial plastic shear modulus, $G^{P}$, as follows:

$$
\begin{aligned}
& A^{*}=M_{f}^{*}, \\
& B^{*}=\frac{G^{P}}{M_{f}^{*}} .
\end{aligned}
$$

In addition, $B^{*}$ follows an equation as

$$
B^{*}=\left(B_{\max }^{*}-B_{1}^{*}\right) \exp \left(-C_{f} d \gamma^{p *}\right) \text {, }
$$

where $B_{1}^{*}$ is the lower boundary of $B^{*}$. Parameter $C_{f}$ controls the rate of hardening, and $B_{\max }^{*}$ is the maximum value of $B^{*}$, which is expressed in

$B_{\max }^{*}= \begin{cases}B_{0}^{*} & \text { before reaching phase transformation, } \\ 1+\frac{B_{0}^{*}}{\gamma_{\mathrm{ap}}^{p *} / \gamma_{r}^{p *}} & \text { after reaching phase transformation, }\end{cases}$

where $B_{0}^{*}$ is a hardening parameter before the stress ratio reaches the phase transformation stress ratio $M_{m}^{*}, \gamma_{r}^{p *}$ is the reference plastic strain, and $\gamma_{\mathrm{ap}}^{p *}$ is accumulative plastic shear strain after phase transformation. Note that the material parameter $C_{f}$ is set to zero in this research.

The kinematical hardening associated with the change in the mean effective stress is given by

$$
\begin{aligned}
y_{m}^{*} & =y_{m 1}^{*}+y_{m 2}^{*}, \\
d y_{m 1}^{*} & =B_{2}^{*}\left(A_{2}^{*} d \varepsilon_{v}^{p}-y_{m 1}^{*}\left|d \varepsilon_{v}^{p}\right|\right), \\
d y_{m 2}^{*} & =B_{3}^{*} d \varepsilon_{v}^{p},
\end{aligned}
$$

where $A_{2}^{*}, B_{2}^{*}$, and $B_{3}^{*}$ are material constants and $d \varepsilon_{v}^{p}$ is the volumetric plastic increment.

The plastic potential function is given by

$$
g=\bar{\eta}_{\chi}^{*}+\tilde{M}^{*}\left(\ln \frac{\sigma_{m k}^{\prime}}{\sigma_{m p}^{\prime}}+\left|\ln \frac{\sigma_{m}^{\prime}}{\sigma_{m k}^{\prime}}-y_{m}^{*}\right|\right)=0,
$$

where $\sigma_{m p}^{\prime}$ is a constant and $\tilde{M}^{*}$ is the dilatancy parameter whose definition is distinguished between the normally consolidated region and the overconsolidated region, as given in

$$
\tilde{M}^{*}= \begin{cases}M_{m}^{*}, & f_{b} \geq 0\left(\text { normally consolidated region and after stress ratio reached } M_{m}^{*}\right), \\ \left(\frac{\sigma_{m}^{*}}{\sigma_{m b}^{\prime}}\right)^{n_{2}} M_{m}^{*}, & f_{b}<0 \text { (overconsolidated region), }\end{cases}
$$

where $n_{2}$ is a material parameter and $\sigma_{m}^{*}$ is the mean effective stress at the intersection between the surface which passed through the current stress and has the same shape as $f_{b}$, and the anisotropic stress axis. The overconsolidated boundary surface, yield function, and plastic potential function for an isotropic overconsolidated state are illustrated in Figure 3.

Oka and Kimoto [14] used Equation (12) to account for the stress and strain dependency of the elastic shear modulus:

$$
G^{E}=\frac{G_{0}^{E}}{1+\alpha_{e}\left(\gamma_{\mathrm{ap}}^{P *} / \gamma_{r}^{E *}\right)^{r_{e 1}}}\left(\frac{\sigma_{m}^{\prime}}{\sigma_{m 0}^{\prime}}\right)^{r_{e 2}},
$$

where $\alpha_{e}, r_{e 1}$, and $r_{e 2}$ are material parameters and $G_{0}^{E}$ the initial elastic shear modulus. $\gamma_{\text {ap }}^{P^{*}}$ denotes the accumulative plastic deviatoric strain after the stress ratio reaches the phase transformation $M_{m}^{*}$, and $\gamma_{r}^{E *}$ is the reference strain which can be obtained by fitting to liquefaction resistance curve.

3.2. Parametric Study on $C_{n s}$. The effect of nonassociativity parameter $C_{n s}$ in the cyclic elastoplastic model under undrained simple shear conditions was presented in Oka and Kimoto [16] by simulating the behavior of loose Toyoura silica sand. They showed that the parameter $C_{n s}$ controls the minimum mean effective stress during cyclic loading, namely, the minimum mean effective stress is smaller for the case with smaller $C_{n s}$. In this section, a parametric study is performed by using COMVI2D-DY with a 1-D horizontally layered model to demonstrate the effect of $C_{n s}$ on the dynamic behavior and the reconsolidation behavior. The 1- 
TABLE 1: Material parameters of Naruse sand.

\begin{tabular}{|c|c|c|c|}
\hline Soil parameters & & Elastoplastic model [24] & Extended elastoplastic model \\
\hline Initial void ratio & $e_{0}$ & 1.159 & 1.159 \\
\hline Density & $\rho$ & 1.73 & 1.73 \\
\hline Compression index & $\lambda$ & 0.0500 & 0.0500 \\
\hline Swelling index & $\kappa$ & 0.0057 & 0.0057 \\
\hline Normalized initial elastic shear modulus & $\frac{G_{0}}{\sigma_{m 0}^{\prime}}$ & 340 & 340 \\
\hline Water permeability $(\mathrm{m} / \mathrm{s})$ & $k_{w s}$ & $1.13 \times 10^{-4}$ & $1.13 \times 10^{-4}$ \\
\hline Quasi-overconsolidation ratio & OCR $^{*}$ & 1.2 & 1.2 \\
\hline Stress ratio at phase transformation & $M_{m}^{*}$ & 0.891 & 0.891 \\
\hline Stress ratio at failure & $M_{f}^{*}$ & 1.229 & 1.229 \\
\hline Hardening parameter & $B_{0}^{*}$ & 5000 & 5000 \\
\hline Hardening parameter & $B_{1}^{*}$ & 100 & 100 \\
\hline Hardening parameter & $C_{f}$ & 0 & 0 \\
\hline Dilatancy coefficient & $D_{0}^{*}$ & 1.0 & 1.0 \\
\hline Dilatancy coefficient & $n$ & 6.0 & 6.0 \\
\hline Reference value of plastic strain & $\gamma_{r}^{p *}$ & 0.001 & 0.001 \\
\hline Reference value of elastic strain & $\gamma_{r}^{E *}$ & 0.003 & 0.003 \\
\hline Hardening parameter & $A_{2}^{*}$ & - & 0.0 \\
\hline Hardening parameter & $B_{2}^{*}$ & - & 0.0 \\
\hline Hardening parameter & $B_{3}^{*}$ & - & 40.47 \\
\hline Elastic shear modulus parameter & $r_{e 2}$ & - & 1.0 \\
\hline Elastic shear modulus parameter & $\alpha_{e}$ & - & 1.0 \\
\hline Elastic shear modulus parameter & $r_{e 1}$ & - & 1.0 \\
\hline Anisotropy disappearance parameter & $C_{d}$ & 2000.0 & 2000.0 \\
\hline Nonassociativity flow rule & $C_{n s}$ & - & Parametric study \\
\hline Stiffness recovery rate & $C_{c f}$ & - & $2000^{*}$ \\
\hline
\end{tabular}

*This parameter is not used in the parametric study.

D model consists of 10 elements with a total height of $30 \mathrm{~m}$ and a width of $3 \mathrm{~m}$ as shown in Figure 4 . The bottom boundary of the model is perfectly fixed, and the equal nodal displacements on both sides are assumed at the same depth. A pervious boundary with a zero static pore water pressure is set at the top of the model while an impervious boundary is set for the other boundaries. The ground motion of the 2011 Tohoku earthquake recorded at a depth of $80 \mathrm{~m}$ at the Tajiri earthquake observation station in Miyagi Prefecture [25] is used. The acceleration profile is shown in Figure 5. The dynamic loading lapses after 200 seconds; the modelled soil column is then allowed to consolidate for 10 days. Material parameters used in this parametric are shown in Table 1 in the right column, which is determined for Naruse River sand in Miyagi Prefecture.

The effect of nonassociativity parameter $C_{n s}$ is revealed by comparing analysis Case 1: $C_{n s}=0.02$, Case 2: $C_{n s}=0.2$, and Case 3: $C_{n s}=0.5$. Figures $6(\mathrm{a})$ and $6(\mathrm{~b})$ show the time history of the pore water pressure and the mean effective stress of element 8 . It can be observed that $C_{n s}$ has almost no effect on the excess pore water pressure generation during dynamic loading. However, a higher value of $C_{n s}$ leads to faster dissipation of the excess pore water pressure during reconsolidation, as well as a faster recovery of the mean effective stress. The final surface settlements of case 1 , case 2 , and case 3 are $0.68 \mathrm{~m}, 1.11 \mathrm{~m}$, and $1.18 \mathrm{~m}$, respectively, as shown in Figure 6(c). It appears that the value of $C_{n s}$ has significant influence on consolidation settlement. It is worth noting that associate flow rule $\left(C_{n s}=1.0\right)$ is assumed during consolidation analysis for all the three cases. Therefore, the difference in consolidation settlement between each case is due to the combination effect of the $C_{n s}$ value and accumulative plastic strain during dynamic analysis.

Moreover, $C_{n s}$ controls the reduction of mean effective stress when soil liquefies, together with the nonlinear kinematic hardening parameter $y_{m}^{*}$. Therefore, the minimum mean effective stress is larger in Case 3 than in Case 1 as shown in Figure 6(d). This tendency agrees with the results shown in Oka and Kimoto [16]. Besides, the response of stress due to ground acceleration is slightly smaller for larger 

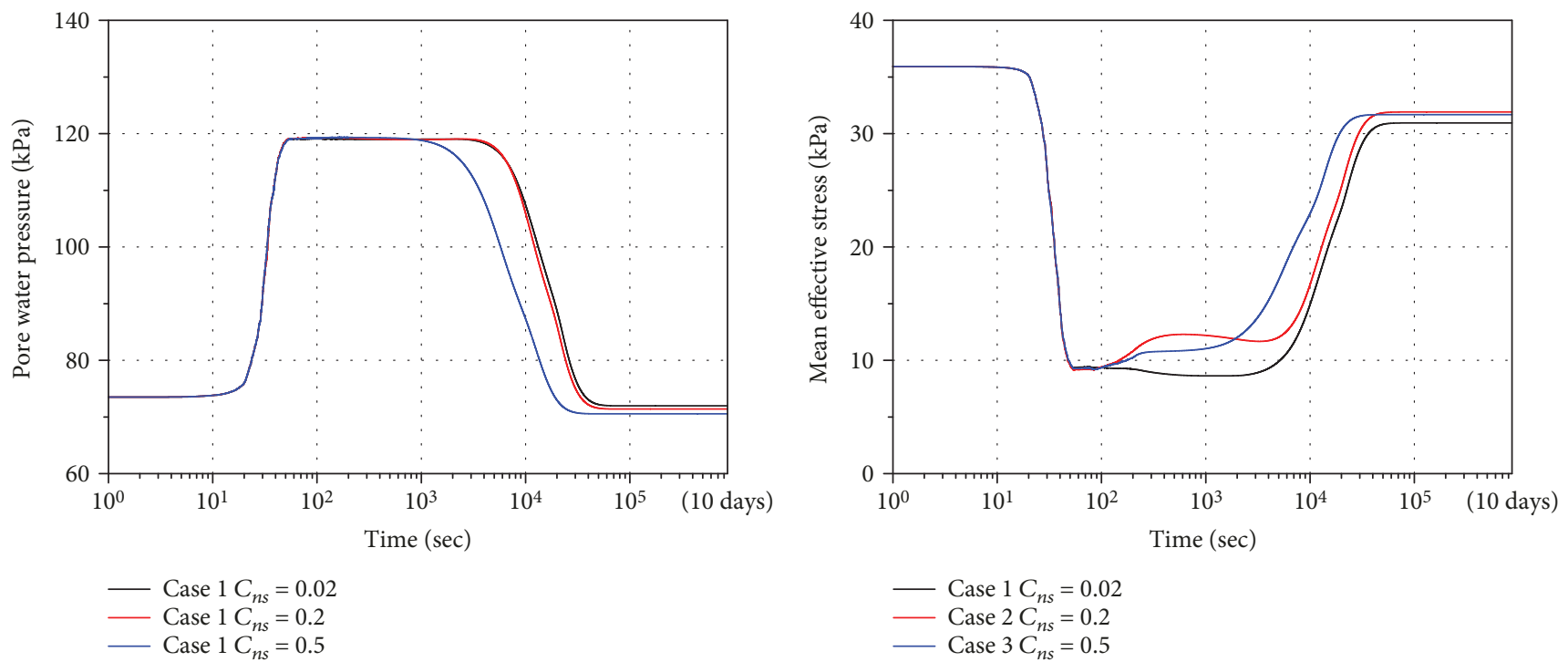

(a) Effect of $C_{n s}$ on time history of pore water pressure of element 8

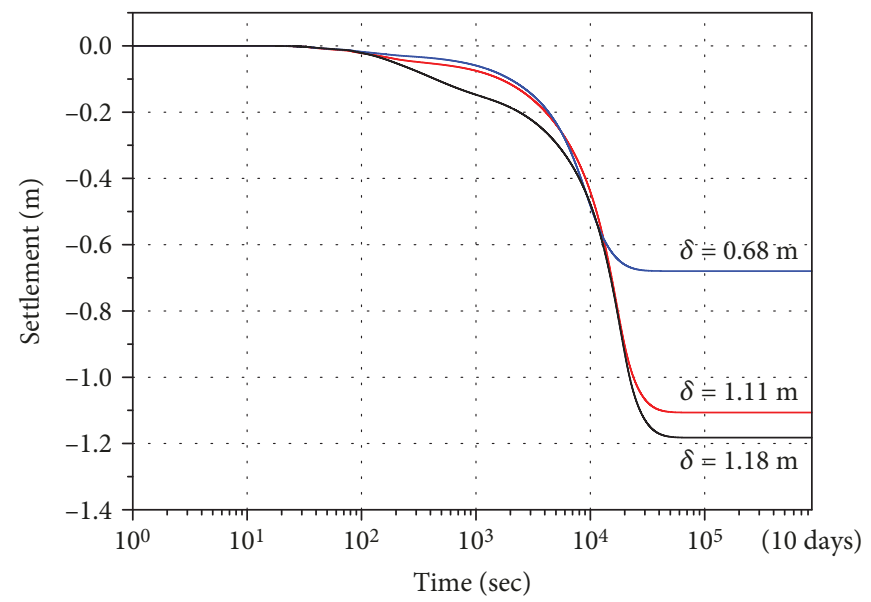

(b) Effect of $C_{n s}$ on time history of mean effective stress of element 8

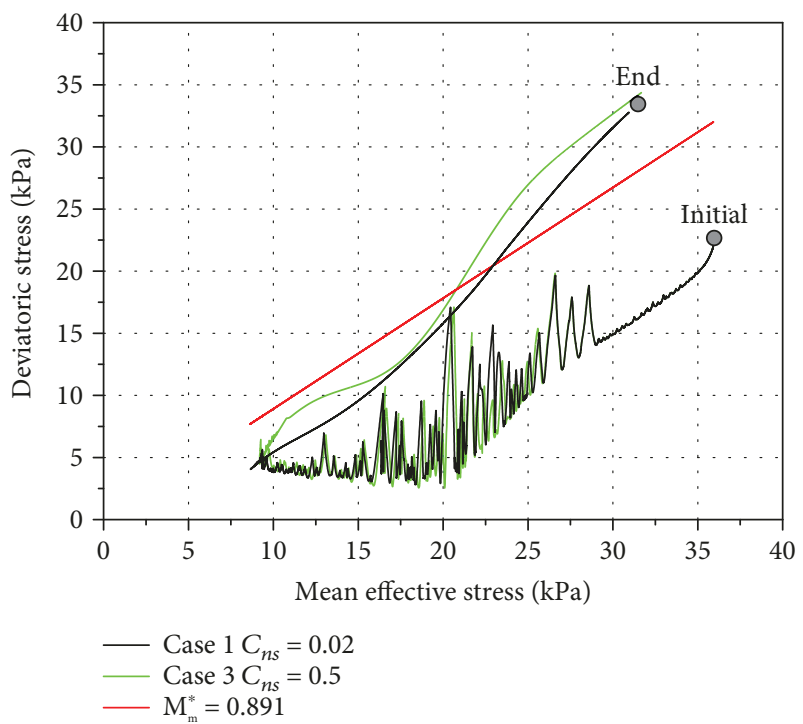

(d) Stress path of element 8 for Naruse sand with Case 1 and Case 3

(c) Effect of $C_{n s}$ on time history of surface settlement

Figure 6: Parametric study on $C_{n s}$.

$C_{n s}$. Such a mechanism is important for not only the realistic soil behavior simulation but also the stability of numerical calculation. Furthermore, larger increase in stress ratio in Case 3 is found during consolidation than that in Case 1. This is due to the higher stiffness of soil in Case 3 which would result in a higher response stress.

From the parametric study, it was found that the parameter $C_{n s}$ has a significant influence on consolidation settlement, that is, a larger value of $C_{n s}$ gives smaller settlement for this set of parameters. It should be noted, however, that the model with strong nonassociativity with a small value of $C_{n s}$ has a potential for simulating liquefaction while the model with the associated flow rule does not as mentioned in Oka and Kimoto [16]. In other words, a large value of $C_{n s}$ may not be appropriate to simulate liquefaction behavior.
3.3. Modification of the Model considering Stiffness Recovery. In the elastoplastic constitutive model shown in the previous section, the reduction of the elastic stiffness $G^{E}$ and the plastic stiffness $B^{*}$ with increasing deviatoric strain was given in (8) and (12). In the following, the elastic and plastic stiffness recovery during reconsolidation is introduced in the model.

The elastic shear modulus is extended to incorporate the hardening effect of volumetric strain compression during reconsolidation in the form of

$$
\begin{aligned}
G^{E}= & \frac{G_{0}^{E}}{1+\alpha_{e}\left(\gamma_{\mathrm{ap}}^{P *} / \gamma_{r}^{E *}\right)^{r_{e 1}}}\left(\frac{\sigma_{m}^{\prime}}{\sigma_{m 0}^{\prime}}\right)^{r_{e 2}} \\
& +G_{f}^{E}-G_{f}^{E} \exp \left(-C_{c f} \Delta \varepsilon_{v}\right)
\end{aligned}
$$




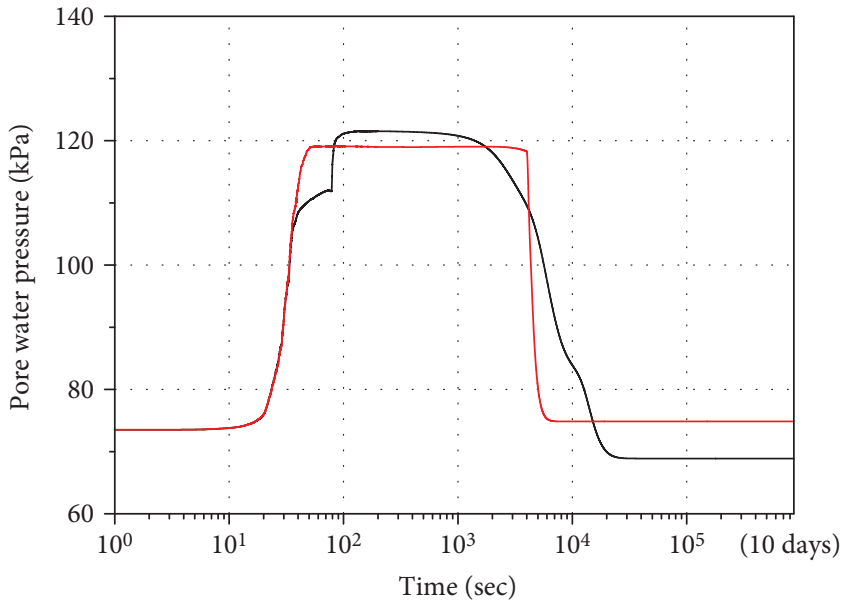

Cyclic elastoplastic model

Extended cyclic elastoplastic model

(a) Comparison of time history of pore water pressure

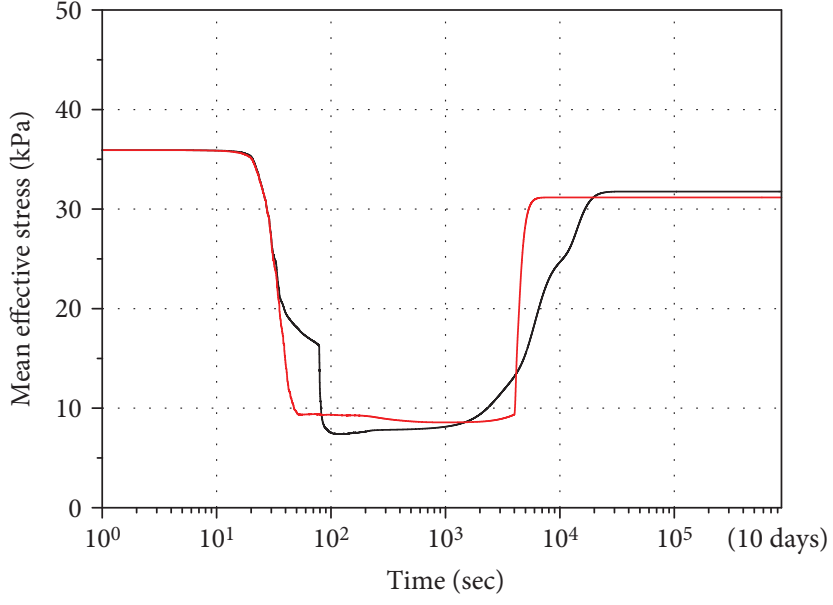

Cyclic elastoplastic model

Extended cyclic elastoplastic model

(b) Comparison of time history of mean effective stress

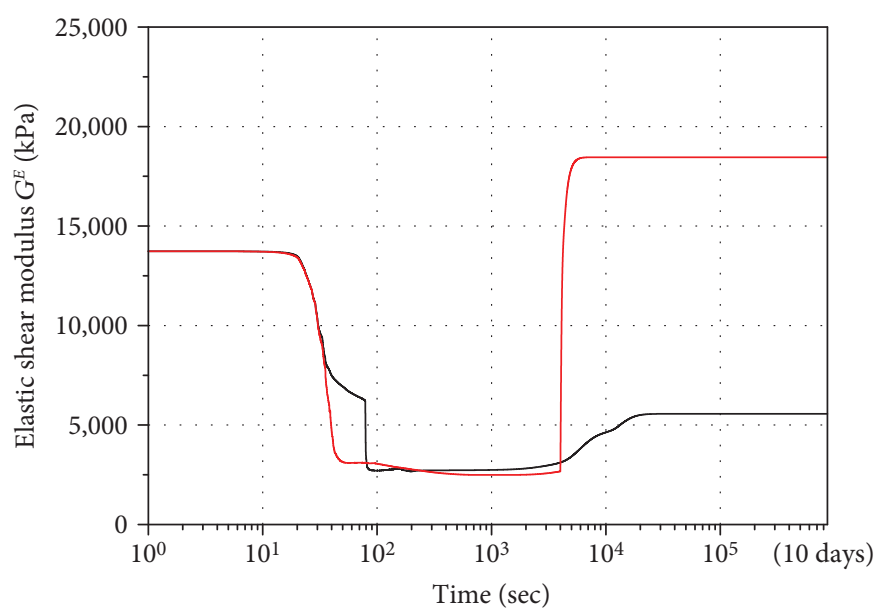

- Cyclic elastoplastic model

- Extended cyclic elastoplastic model

(c) Comparison of time history of elastic shear modulus $G^{E}$

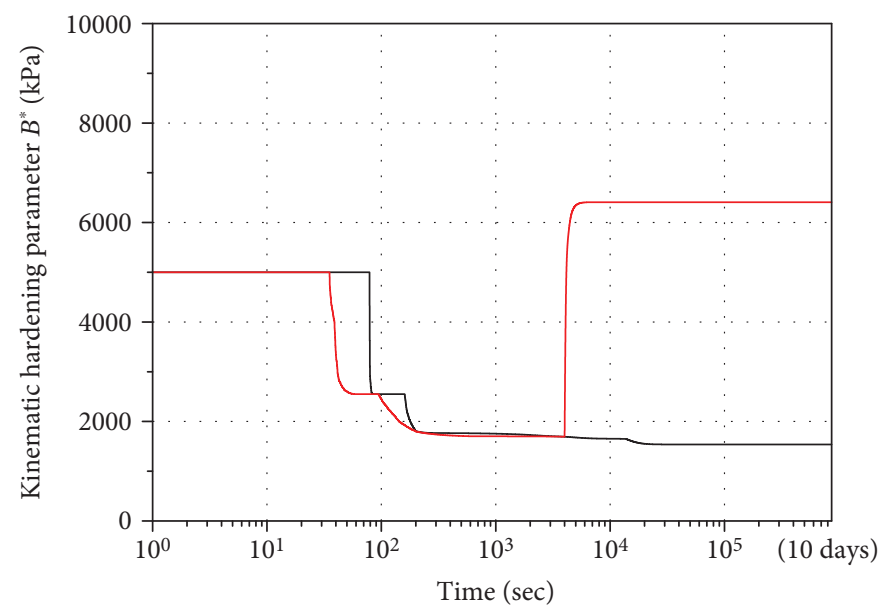

Cyclic elastoplastic model

Extended cyclic elastoplastic model

(d) Comparison of time history of kinematic hardening parameter $B^{*}$

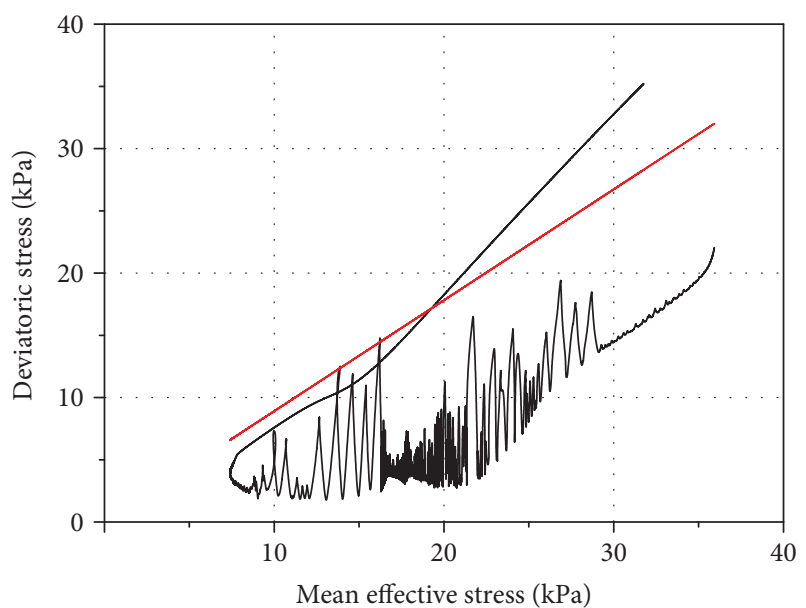

Cyclic elastoplastic model

$-\mathrm{M}_{m}^{*}=0.891$

(e) Stress path of element 8 for cyclic elastoplastic model

Figure 7: Continued. 


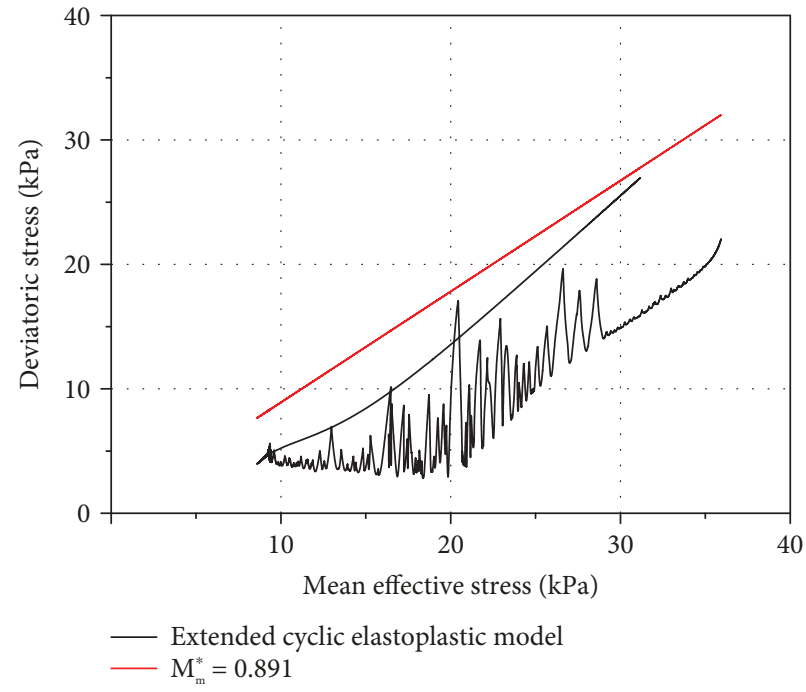

(f) Stress path of element 8 for extended cyclic elastoplastic model

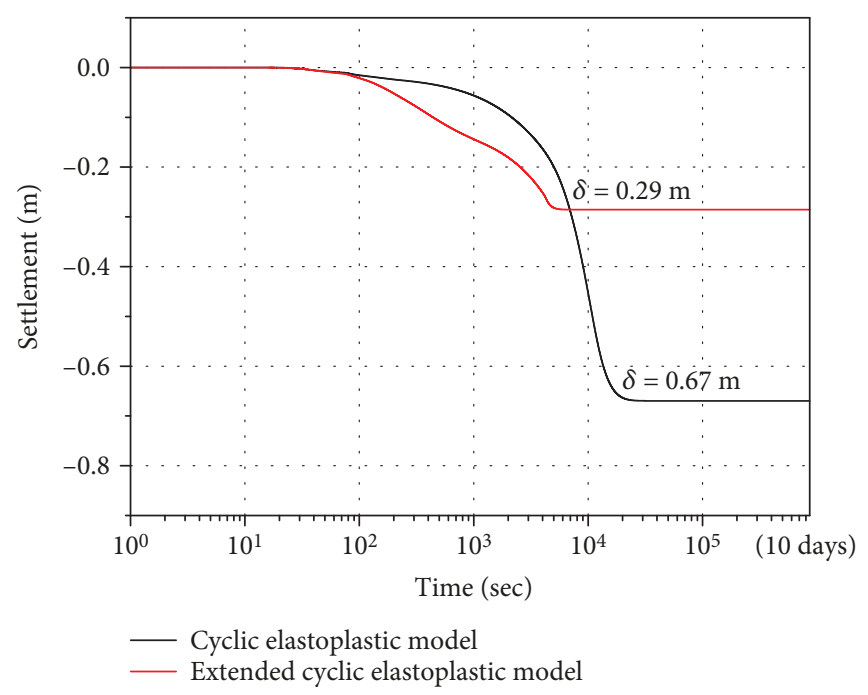

(g) Comparison of time history of settlement

Figure 7: Comparison between the original elastoplastic model and the modified elastoplastic model.

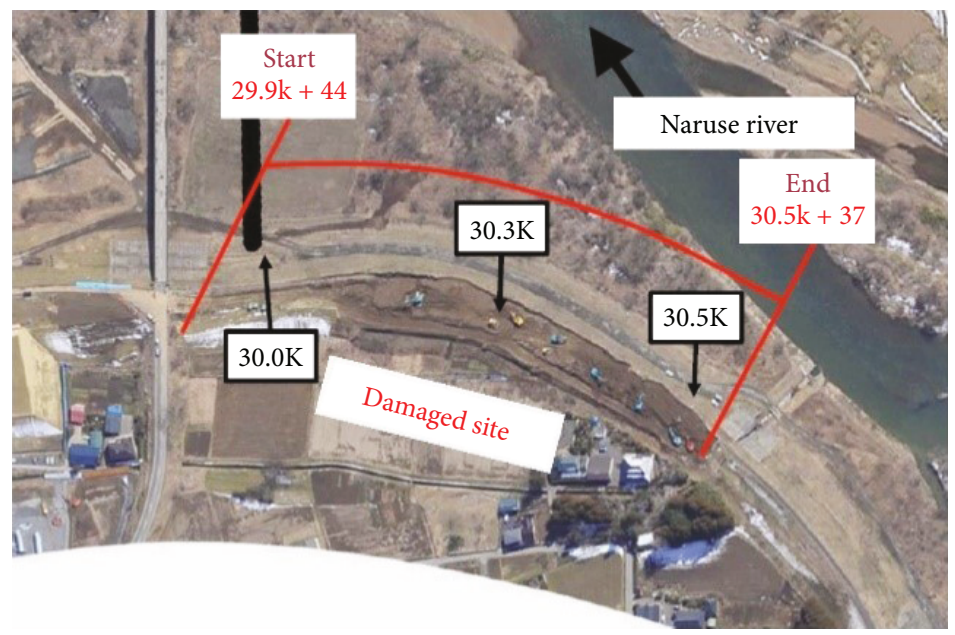

FIgURE 8: Location of the damaged site along the Naruse River [2].

in which $G_{f}^{E}$ is a material parameter that represents the value of final elastic shear modulus at the end of consolidation and $C_{c f}$ is a material parameter to control the recovery rate of elastic shear modulus during consolidation. The accumulative volumetric compression after dynamic loading, namely, during reconsolidation, is denoted by $\Delta \varepsilon_{v}$. Equation (13) separates the hardening component attained from volumetric compression, that is, consolidation, from that attained during dynamic shearing. In addition, it is assumed that $G^{E}$ is not affected by the change of plastic deviatoric strain during consolidation. In other words, $\gamma_{\mathrm{ap}}^{P_{*}^{*}}$ is constant.

Similar to the elastic shear modulus, the hardening term is considered in the plastic shear modulus $B^{*}$ during consolidation which is associated with the volumetric compression:

$$
B^{*}=1+\frac{B_{0}^{*}}{\gamma_{\mathrm{ap}}^{p *} / \gamma_{r}^{p *}}+B_{f}^{*}-B_{f}^{*} \exp \left(-C_{c f} \Delta \varepsilon_{v}\right)
$$

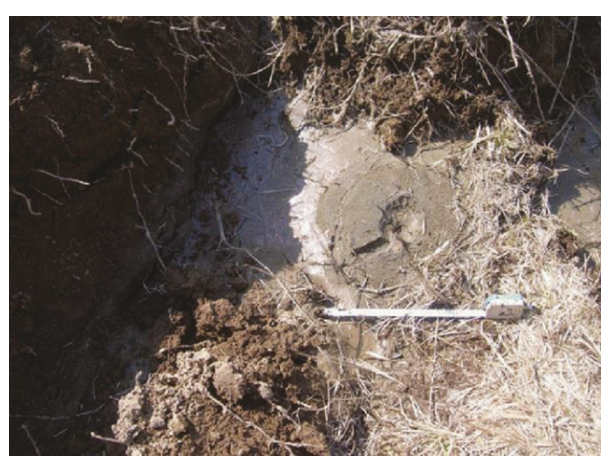

FIGURE 9: Sand boiling in the embankment crack [27].

where $B_{f}^{*}$ is the material parameter and equals the value of recovery at the end of consolidation. Ye et al. [26] experimentally investigated the stiffness recovery of liquefied sandy 


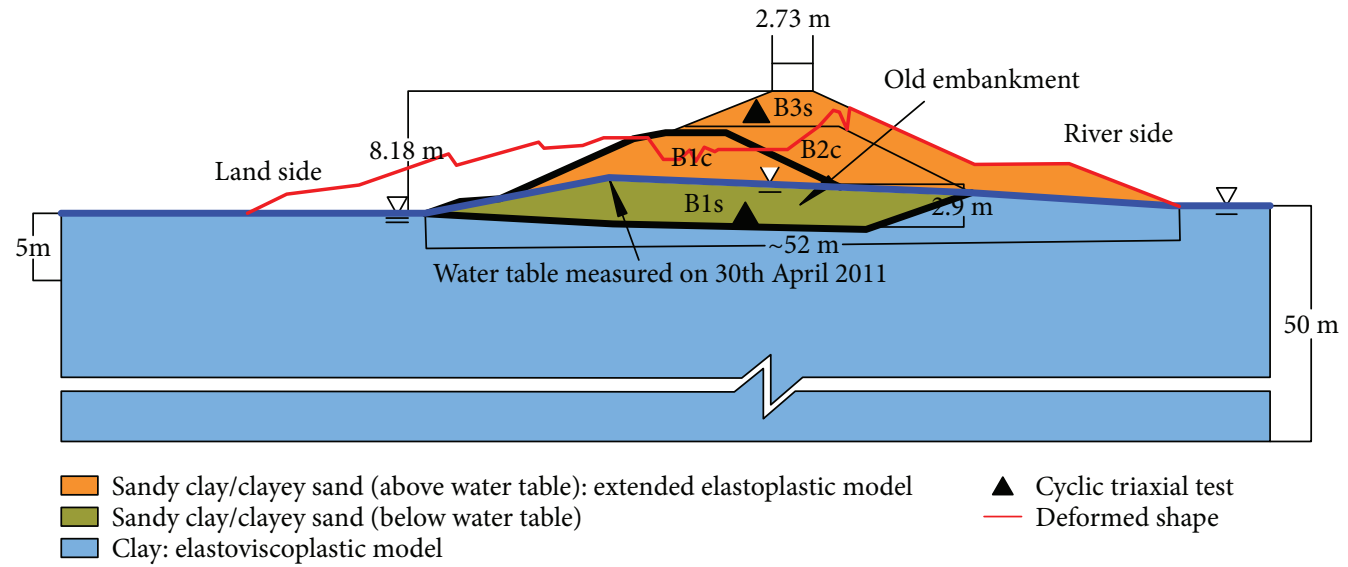

Figure 10: Cross section of river embankment at Shimonakanome upper stream of Naruse River (30.3 km).

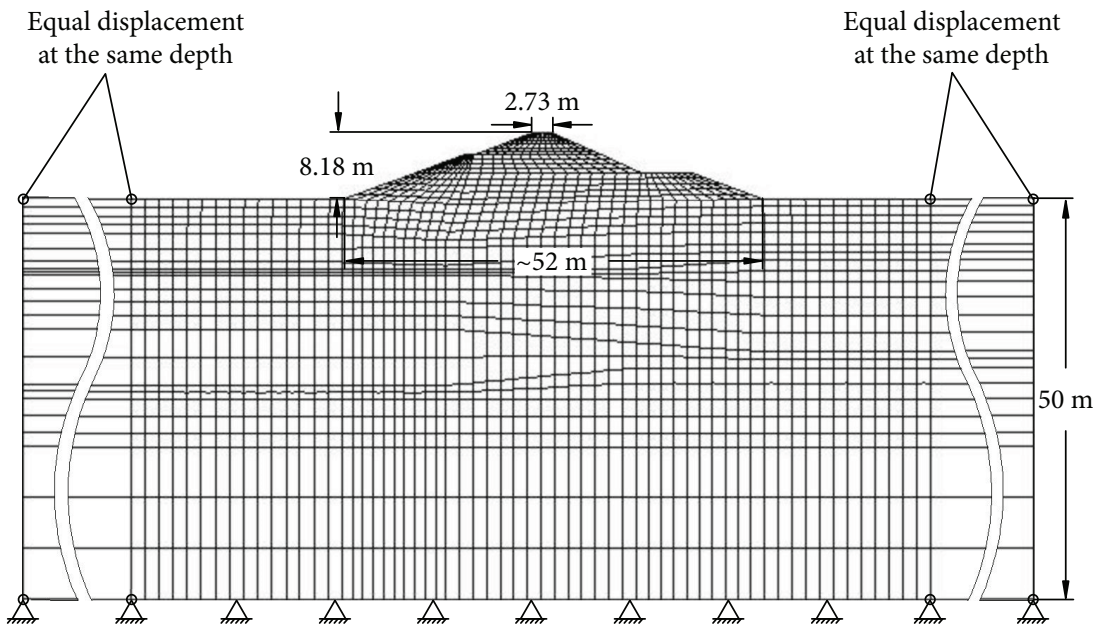

FIgURE 11: Finite element mesh and boundary conditions.

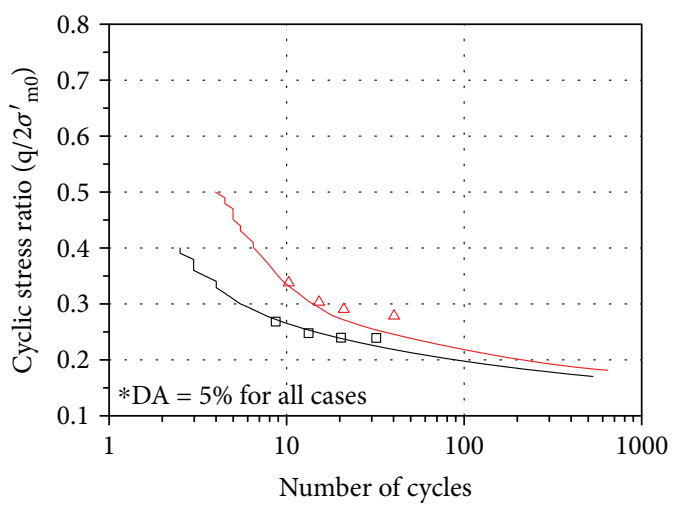

- Cyclic triaixal test-B3s (MLIT, 2011)

$\triangle \quad$ Cyclic triaixal test-B1s (MLIT, 2011)

- Simulation-B3s

- Simulation-B1s

FIGURE 12: Liquefaction resistance curve for embankment fill.

ground and showed that the stiffness after earthquake motion was the same or larger than that before the earthquake. In the present study, $G_{f}^{E}=G_{0}^{E}$ and $B_{f}^{*}=B_{0}^{*}$ are assumed.

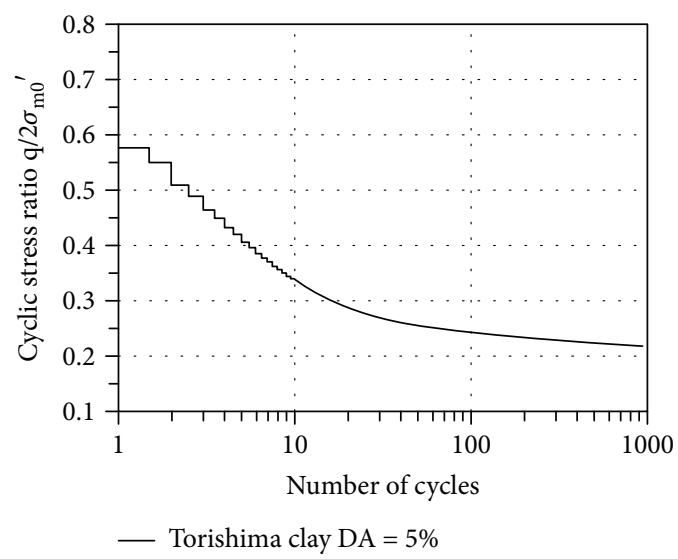

FIgURE 13: Liquefaction resistance curve for Torishima clay.

A comparison between the original elastoplastic model [24] in which the yield function is given by the stress ratio, and the extended elastoplastic model with stiffness recovery will be presented in the following. The exercise is mainly to demonstrate the stiffness recovery ability of the modified model with modifications in the current research. The same 
TABLE 2: Soil parameters for damaged river embankment.

\begin{tabular}{|c|c|c|c|c|}
\hline Soil parameters & & $\mathrm{B} 1 \mathrm{~s} / \mathrm{B} 1 \mathrm{c}$ & $\mathrm{B} 3 \mathrm{~s} / \mathrm{B} 2 \mathrm{c}$ & Foundation \\
\hline Initial void ratio & $e_{0}$ & 1.159 & 1.100 & 1.456 \\
\hline Density & $\rho$ & 1.73 & 1.74 & 1.66 \\
\hline Compression index & $\lambda$ & 0.0500 & 0.0500 & 0.5930 \\
\hline Swelling index & $\kappa$ & 0.0057 & 0.0057 & 0.027 \\
\hline Normalized initial elastic shear modulus & $\frac{G_{0}}{\sigma_{m 0}^{\prime}}$ & 340 & 1020 & 255 \\
\hline Water permeability $(\mathrm{m} / \mathrm{s})$ & $k_{w s}$ & $1.11 \times 10^{-6}$ & $2.66 \times 10^{-7}$ & $8.10 \times 10^{-9}$ \\
\hline Quasi-overconsolidation ratio & OCR $^{*}$ & 1.2 & 1.2 & 1.0 \\
\hline Stress ratio at phase transformation & $M_{m}^{*}$ & 0.891 & 0.891 & 0.891 \\
\hline Stress ratio at failure & $M_{f}^{*}$ & 1.229 & 1.229 & 0.891 \\
\hline Hardening parameter & $B_{0}^{*}$ & 5000 & 2000 & 100 \\
\hline Hardening parameter & $B_{1}^{*}$ & 100 & 100 & 40 \\
\hline Hardening parameter & $C_{f}$ & 0 & 0 & 10 \\
\hline Dilatancy coefficient & $D_{0}^{*}$ & 1.0 & 1.0 & - \\
\hline Dilatancy coefficient & $n$ & 6.0 & 6.0 & - \\
\hline Reference value of plastic strain & $\gamma_{r}^{p *}$ & 0.001 & 0.001 & - \\
\hline Reference value of elastic strain & $\gamma_{r}^{E *}$ & 0.003 & 0.003 & - \\
\hline Viscoplastic parameter & $m^{\prime}$ & - & - & 24.68 \\
\hline Viscoplastic parameter $(1 / \mathrm{s})$ & $C_{1}$ & & & $1.00 \times 10^{-6}$ \\
\hline Viscoplastic parameter $(1 / \mathrm{s})$ & $C_{2}$ & & & $3.83 \times 10^{-7}$ \\
\hline Hardening parameter & $A_{2}^{*}$ & 0.0 & 0.0 & 5.9 \\
\hline Hardening parameter & $B_{2}^{*}$ & 0.0 & 0.0 & 1.8 \\
\hline Hardening parameter & $B_{3}^{*}$ & 50.11 & 41.6 & - \\
\hline Elastic shear modulus parameter & $r_{e 2}$ & 1.0 & 1.0 & - \\
\hline Elastic shear modulus parameter & $\alpha_{e}$ & 1.0 & 1.0 & - \\
\hline Elastic shear modulus parameter & $r_{e 1}$ & 1.0 & 1.0 & - \\
\hline Anisotropy disappearance parameter & $C_{d}$ & 2000 & 2000 & - \\
\hline Nonassociativity flow rule & $C_{n s}$ & 0.02 & 0.02 & - \\
\hline Stiffness recovery rate* & $C_{c f}$ & 2000 & 2000 & - \\
\hline
\end{tabular}

*This parameter is not used in dynamic analysis.

model configuration, drainage conditions, boundary conditions, and loading conditions as those used in the previous section are adopted. Material parameters are shown in Table $1 . C_{n s}=0.02$ is chosen for the case of strong nonassociativity, similar to the cyclic elastoplastic model. The hardening parameter $B_{3}^{*}$ is set to be $\left(1+e_{0}\right) /(\lambda-\kappa)=40.47$. It was widely understood that liquefied soil would experience a low-rigidity period before the stiffness recovery. Therefore, the onset of consolidation in the case of using the extended model is set to be 4000 seconds, which correspond to the time lapse before the excess pore water pressure starts to dissipate in the case of the original model.

Simulation results are shown in Figures $7(\mathrm{a})-7(\mathrm{~g})$ for element 8. It is observed that the cyclic elastoplastic model [24] experienced higher excess pore water pressure during dynamic loading than the extended model. This is mainly due to the combination effect of $C_{n s}$ and the kinematic hardening term. Figure 7(b) shows the comparison of the mean effective stress of element 8 , in which the elastoplastic model experienced lower mean effective stress. The effect of volumetric compression hardening on stiffness recovery is depicted in Figures 7(c) and 7(d). Figure 7(c) shows the recovery of elastic shear modulus, whereas the recovery of the kinematic hardening parameter $B^{*}$, which is related to soil plastic stiffness, is shown in Figure $7(\mathrm{~d})$. The stiffness recovers effectively and ends with a higher final stiffness than the initial one. Note that the amount of stiffness recovery at the end of consolidation is an input parameter and should be determined from experimental data. However, due to the lack of information, they are assumed to be equal to the initial stiffness value. Figures $7(\mathrm{e})$ and $7(\mathrm{f})$ show the effective stress path of element 8 for the original elastoplastic model 
TABLE 3: Soil-water characteristic curve and hydraulic parameters.

\begin{tabular}{lcc}
\hline Water characteristic parameters & & Embankment fill \\
\hline van Genuchten parameter $(1 / \mathrm{kPa})$ & $\alpha$ & 0.275 \\
van Genuchten parameter & $n^{\prime}$ & 1.23 \\
Minimum saturation & $S_{\min }$ & 0.00 \\
Maximum saturation & $S_{\max }$ & 0.99 \\
Water permeability shape parameter & $a$ & 3 \\
Gas permeability shape parameter & $b$ & 1 \\
Suction parameter & $S_{I}$ & 0.2 \\
Suction parameter & $S_{d}$ & 0.1 \\
Suction parameter & $S_{I B}$ & 0.2 \\
Suction parameter & $S_{d b}$ & 0.1 \\
\hline
\end{tabular}

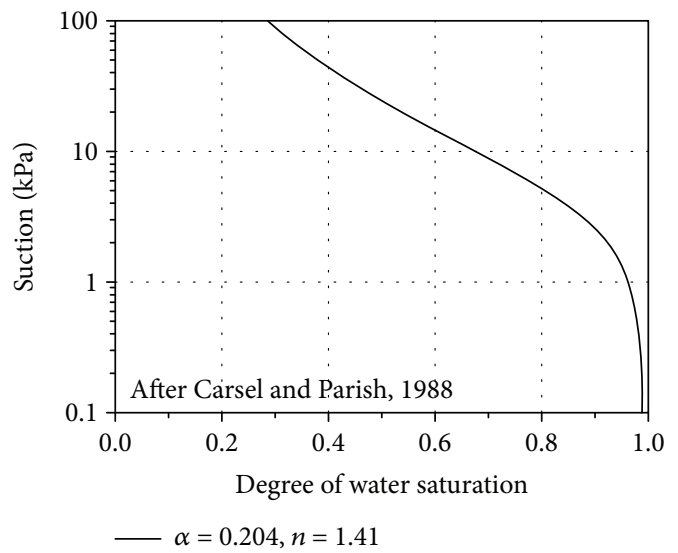

FIgURE 14: Soil-water characteristic curve used for Naruse soil.

and extended elastoplastic model, respectively. The minimum mean effective stress is smaller in the original model. Significant distinction is observed in Figure $7(\mathrm{~g})$ - the total settlement of the case with the elastoplastic model is $0.67 \mathrm{~m}$ whereas that of the case with the extended model is $0.29 \mathrm{~m}$. This is due to the effect of kinematic hardening and stiffness during consolidation. Such a result is reasonable because it is not realistic for sandy soil to have much larger settlement due to consolidation than during liquefaction.

\section{Numerical Analysis of River Embankment during Earthquake and Reconsolidation}

4.1. Model Description. The target river embankment is located at Shimonakanome upper stream of Naruse River, $30.3 \mathrm{~km}$ from the river mouth. The location of the embankment is shown in Figure 8. This embankment was found heavily damaged after the 2011 Tohoku earthquake. According to the investigation report [27], boiling sand was observed in the longitudinal cracks as shown in Figure 9. In addition, the presence of ground water in the embankment was confirmed. Therefore, it was concluded by MLIT [2] that

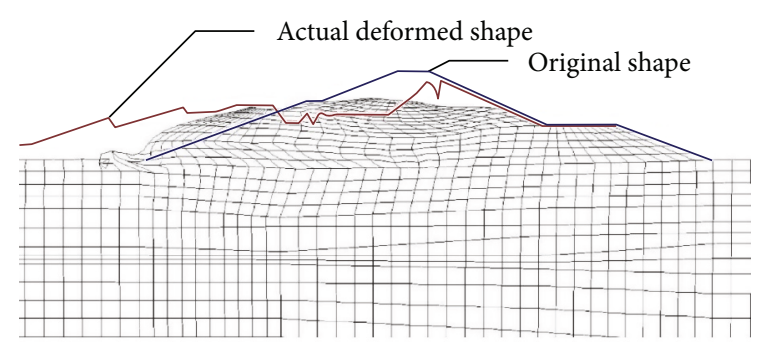

FIgURE 15: Comparison between deformed mesh, original embankment shape, and actual deformed shape.

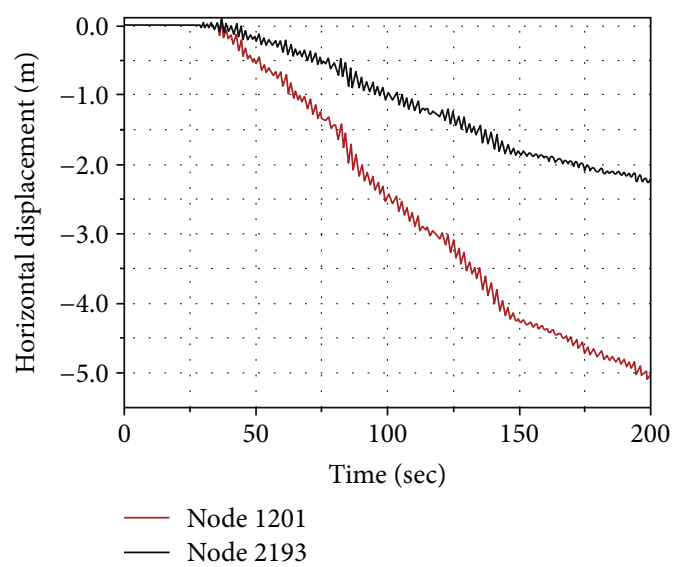

FIgURE 16: Time history of horizontal displacement for node 1201 and node 2193 .

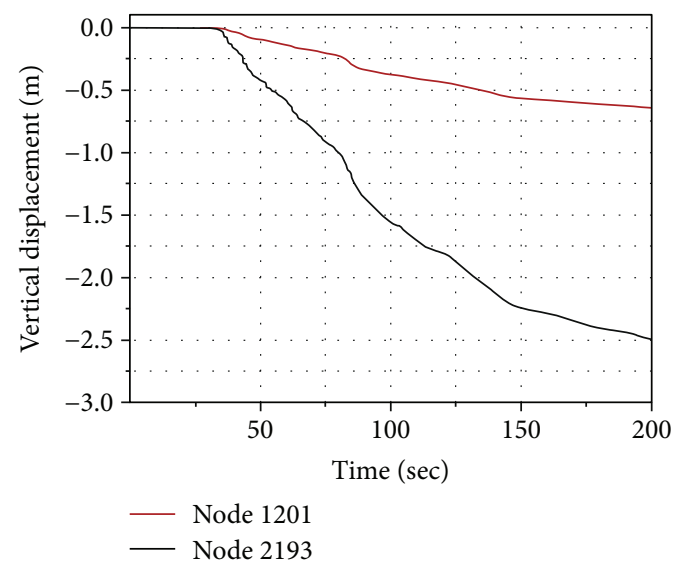

FIgURE 17: Time history of vertical displacement for node 1201 and node 2193 .

the failure of river embankment is caused by liquefaction of the embankment fill.

A cross section of the river embankment including its geometry, geological stratigraphy, and the location of the water table is shown in Figure 10. The liquefied soil is identified as clayey sand (B1s) with a maximum thickness of $2.9 \mathrm{~m}$. According to the geological map of Naruse River, this river embankment was a natural levee [28] which was indicated as "old embankment" in Figure 10. The old embankment was formed by sandy soil (B1c and B1s) and then enlarged twice using sand and clay material. The location 


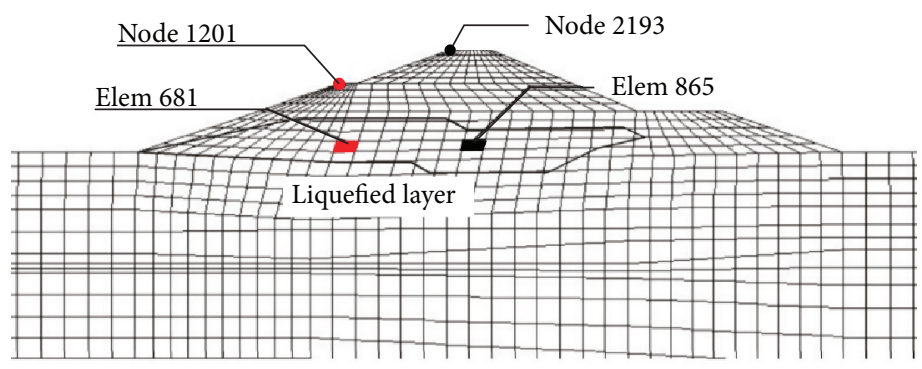

Figure 18: Location of focused nodes and elements.

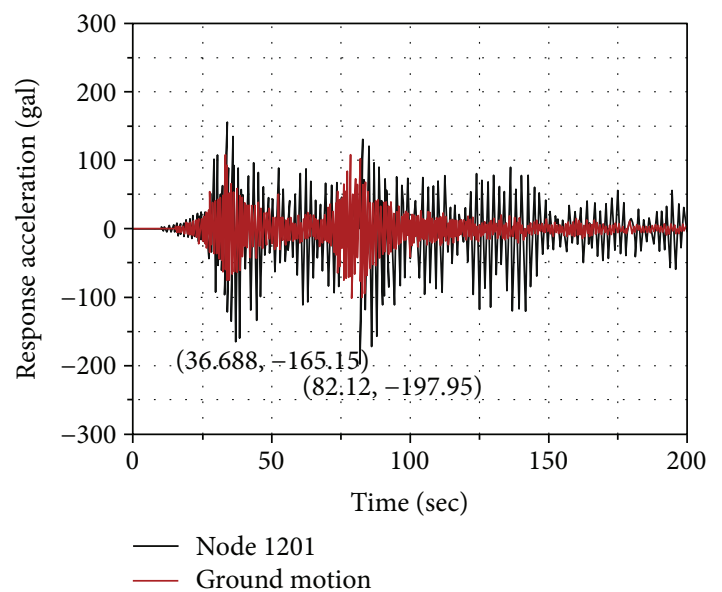

Figure 19: Time history of response horizontal acceleration for node 1201 .

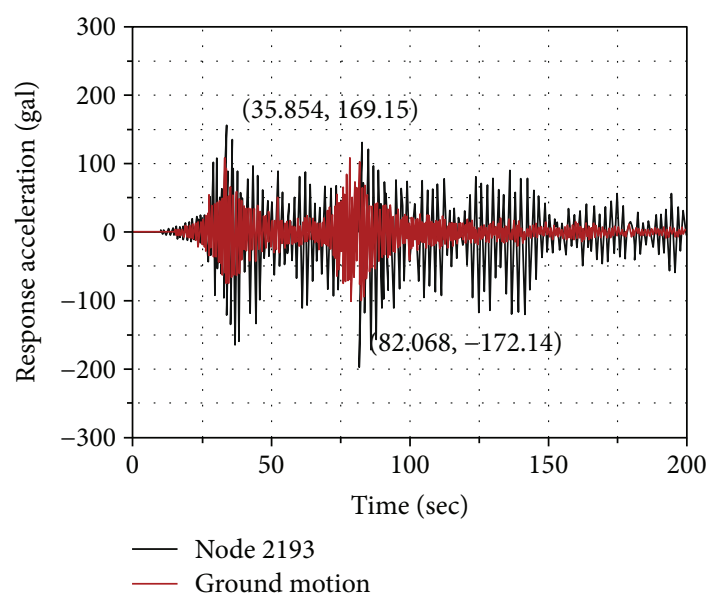

FIgURE 20: Time history of response horizontal acceleration for node 2193.

of ground water table is indicated by the blue line, which was measured on site one month after the earthquake. The deformation shape is illustrated in Figure 10 as well. It could be observed that large sliding occurred towards the land side, after liquefaction.

Geometry of the finite element model, the mesh, and the boundary conditions are depicted in Figure 11. The numerical simulation was conducted under 2-D plane strain condition. A full-scale model was considered with an engineering

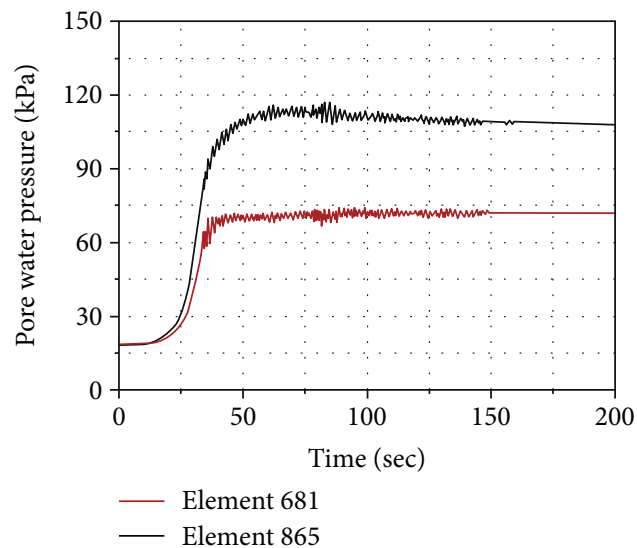

FIGURE 21: Time history of pore water pressure for element 681 and element 865 during dynamic analysis.

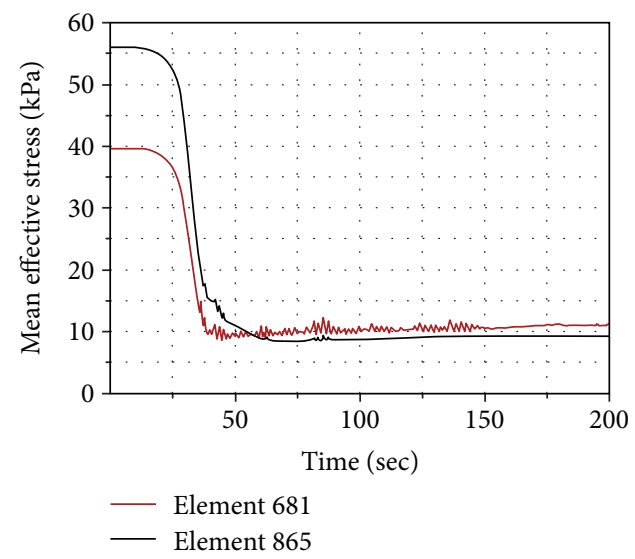

FIgURE 22: Time history of mean effective stress for element 681 and element 865 during dynamic analysis.

datum of $50 \mathrm{~m}$ below ground level. To reduce the side boundary effects, semi-infinite elements with equidisplacement conditions were used on the left and right ends, each being $100 \mathrm{~m}$ long. Drainage boundary is set at ground level where the initial pore water pressure is zero. A no-water-flow boundary is prescribed along the surface of the embankment to avoid unrealistic water inflow due to suction. Regarding the mesh size in the vertical direction, it is generally determined to be $1 / 5$ of the minimum wavelength in dynamic FEM analysis. For example, when the shear wave velocity is $100 \mathrm{~m} / \mathrm{s}$ and the target maximum frequency is $10 \mathrm{~Hz}$, 


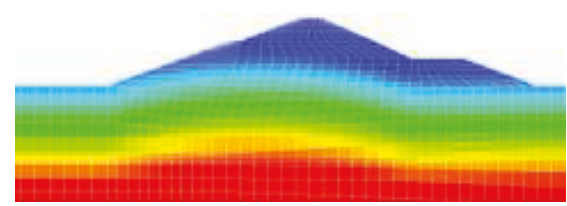

(a) Initial

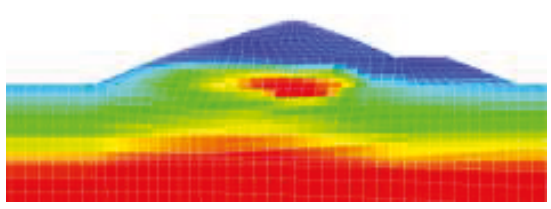

(b) $60 \mathrm{~s}$

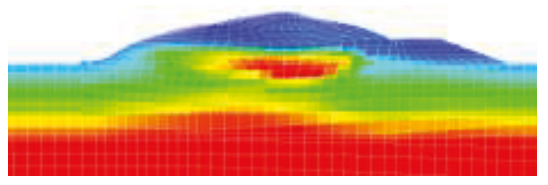

(c) $100 \mathrm{~s}$

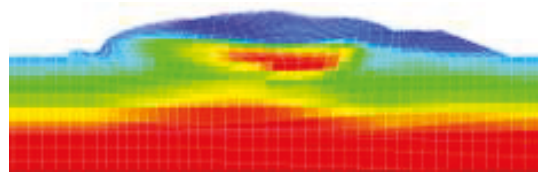

(d) $200 \mathrm{~s}$

\begin{tabular}{llllll}
\hline 19.1 & 8.7 & 36.5 & 64.4 & 92.2 & 120.0
\end{tabular}

FIGURE 23: Distribution of pore water pressure (unit: $\mathrm{kPa}$ ).

the minimum wavelength is $10 \mathrm{~m}$; thus, the required mesh size is $2 \mathrm{~m}$. In the present analysis, the vertical mesh size of the embankment is determined to be around $0.5 \mathrm{~m}$ considering the change of the shear wave velocity and the frequency after liquefaction.

Ground acceleration of the Tohoku earthquake recorded at a depth of $80 \mathrm{~m}$ at Tajiri station in Miyagi Prefecture shown in Figure 5 was used during dynamic analysis, which is the same as that was used in the 1-D dynamicreconsolidation analysis. The rigid base is used so that the bottom boundary of the model is fixed. The Tajiri earthquake motion observation station is located approximately $8.7 \mathrm{~km}$ away from the river embankment at Shimonakanome upper stream of Naruse River.

4.2. Material Parameters. In this analysis, sandy soil is modeled by the extended elastoplastic model whereas the elastoviscoplastic model is used for clayey soil. Soil physical tests were carried out and presented in the investigation report of the damaged river embankment in the Tohoku region [2]. It was found that fine content of the embankment fill is generally close to $50 \%$; hence, the extended elastoplastic model is adopted for all the embankment fills for the sake of numerical simplicity. For the partially saturated region above the water table, namely, the B1c, B2c, and B3s

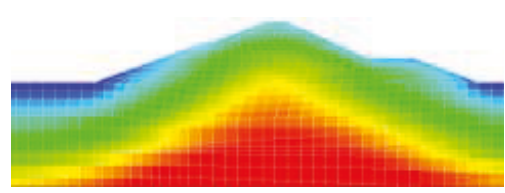

(a) Initial

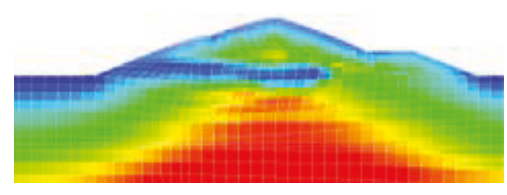

(b) $60 \mathrm{~s}$

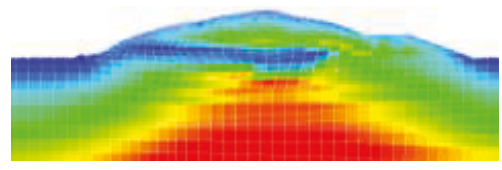

(c) $100 \mathrm{~s}$

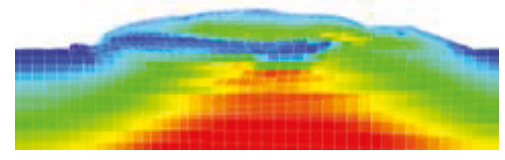

(d) $200 \mathrm{~s}$

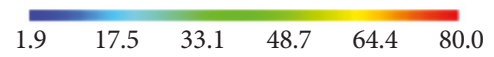

FIGURE 24: Distribution of mean effective stress (unit: $\mathrm{kPa}$ ).

layers, an extended elastoplastic model considering the effect of suction is used, in which the skeleton stress is the basic stress variable and the suction is included in the overconsolidation boundary surface and the yield surface to describe the bonding effect. The embankment is situated on a thick layer of soft clay, which is simulated by the elastoviscoplastic model. Note that the foundation soil is assumed to be homogenous in this analysis.

The cyclic behavior of soil can be represented by a liquefaction resistance curve. Two cyclic triaxial tests were conducted for this river embankment [25]. Location of the soil samples are shown in Figure 10. Due to inadequate experimental results, cyclic behavior of soil B2c and B1c is considered as the same as that of B3s and B1s. Soil test simulation was carried out, and the material parameters are determined to reproduce the results from cyclic triaxial test. The cyclic triaxial test for B3s and B1s and their numerical behavior under cyclic load are plotted in Figure 12. Since the cyclic triaxial test was not carried out for the clayey foundation, material parameters for Torishima clay [13] are adopted since it is a soft alluvium deposit as well. The liquefaction resistance curve of Torishima clay is shown in Figure 13. Material parameters are shown in Table 2, and the suction parameters for the partially saturated region are shown in Table 3.

In COMVI2D-DY, the degree of water saturation depends on the soil-water characteristic curve (SWCC), adopting van Genuchten's [23] model. In Carsel and Parrish 


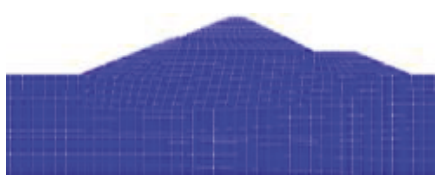

(a) Initial

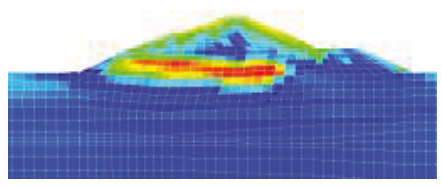

(b) $60 \mathrm{~s}$

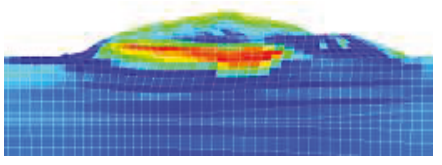

(c) $100 \mathrm{~s}$

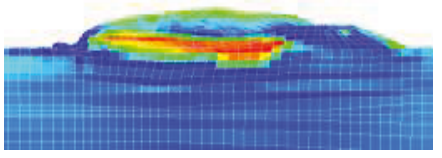

(d) $200 \mathrm{~s}$

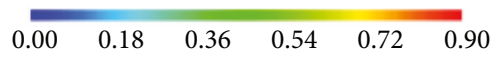

FIGURE 25: Distribution of skeleton stress decreasing ratio (ESDR).

[29], typical values of SWCC parameters, $\alpha$ and $n^{\prime}$, in van Genuchten's model were proposed according to soil descriptions and their permeability. In this simulation, $\alpha$ and $n^{\prime}$, for silt loam, were chosen by considering the soil type and average permeability of the embankment fill. Hydraulic properties and material parameters for the effect of suction for unsaturated soil are listed in Table 3. Since the water table is located above the foundation soil, it is not necessary to consider the soil-water characteristic for soft clay. The SWCC used in the dynamic analysis is shown in Figure 14. The initial degree of saturation above the water table is assumed to be 0.6 , which corresponds to an initial suction of $14.5 \mathrm{kPa}$.

In this analysis, an initial stiffness-dependent type of Rayleigh damping is adopted with an attenuation constant of 0.01 . Time is discretized by Newmark's $\beta$ method where $\beta$ and $\gamma$ are 0.3025 and 0.6 , respectively. The time increment for the dynamic analysis was set to be 0.002 second.

Before conducting the dynamic analysis, the initial effective stress was generated by a static finite element analysis with an elastoperfect plastic model of which the failure surface follows the Drucker-Prager model.

4.3. Dynamic Behavior. The comparison between the original shape of the river embankment, its observed deformed shape after the earthquake, and the deformed mesh from the dynamic analysis at the end of ground acceleration, $200 \mathrm{sec}$, is shown in Figure 15. It could be observed that the embankment is heavily damaged at the end of ground shaking. The

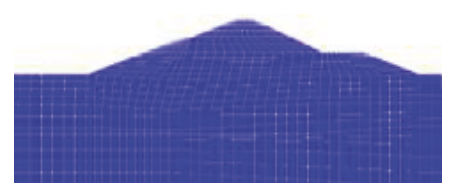

(a) Initial

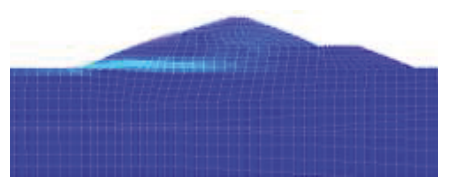

(b) $60 \mathrm{~s}$

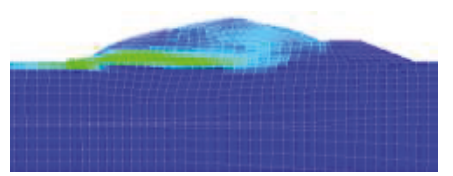

(c) $100 \mathrm{~s}$

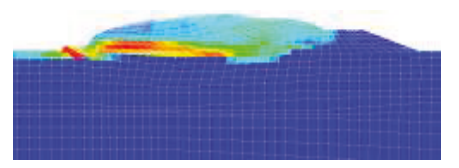

(d) $200 \mathrm{~s}$

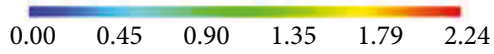

Figure 26: Distribution of accumulative deviatoric plastic strain (GAMP).

key characteristics of the damaged pattern can be reproduced by dynamic analysis. First, the embankment deformed largely towards the land side. Second, part of the embankment on the river side remains undamaged. It appears that the actual deformation on the land side is much larger than that from the simulation. This large lateral spreading of the river embankment is not only due to the collapse of earth structure but also due to the sliding of soil. Such phenomenon is difficult to simulate by finite element analysis since this would involve disconnection between elements or soil particles. In addition, the amount of the simulated deformed soil cannot be compared to that which was observed on-site, since the ground acceleration used in this analysis is not at the exact location of the river embankment.

Time history of the horizontal and the vertical displacements at node 1201 and node 2193 is shown in Figures 16 and 17 , respectively. The locations of node 1201 and node 2193 are depicted in Figure 18. It could be observed that the maximum lateral movements towards the land side and settlement at the top of the embankment are $5.02 \mathrm{~m}$ and $2.50 \mathrm{~m}$, respectively. The simulated settlement at the top of the embankment is close to the observed settlement after the earthquake which is approximately $3 \mathrm{~m}$. However, a lateral displacement of $12 \mathrm{~m}$ was observed on site which is much larger than the simulated one. This result agrees with the previous conclusion that the sliding of earth is difficult to simulate by finite element method. In addition, it can be seen that 


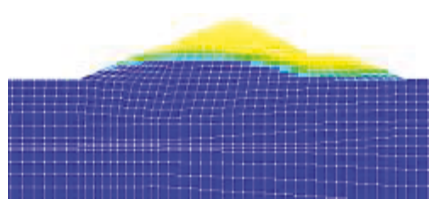

(a) Initial

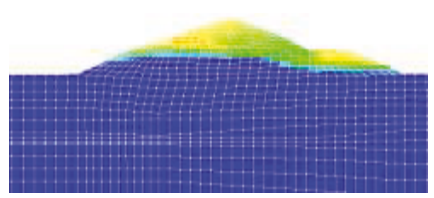

(b) $60 \mathrm{~s}$

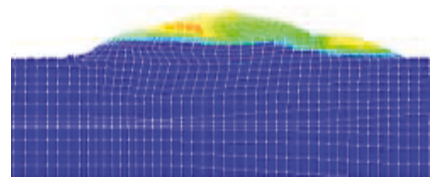

(c) $100 \mathrm{~s}$

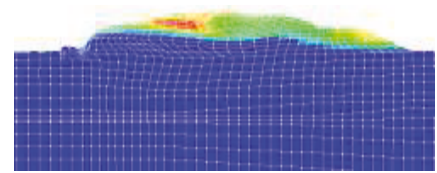

(d) $200 \mathrm{~s}$

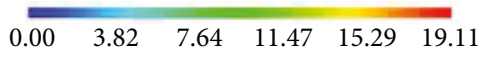

FIGURE 27: Distribution of suction (unit: $\mathrm{kPa}$ ).

both large horizontal and vertical displacements occurred from $30 \mathrm{sec}$ to $150 \mathrm{sec}$ which corresponds to the time period from the start of the first main shock till the end of the second main shock.

Figures 19 and 20 show the acceleration response for node 1201 and node 2193, respectively. Both nodes exhibit acceleration amplification. The peak ground acceleration of the Tohoku earthquake occurs at 33.9 second and $81.2 \mathrm{sec}-$ ond. An average delay of 2 seconds of the peak response can be observed in both nodes. Moreover, although the shaking reduces significantly after 150 seconds, the amplification of acceleration for both nodes remains large. This might be contributed by the viscosity of the soft foundation clay.

Failure mechanism of the river embankment can be clarified by examining the change of pore water pressure, change of stress, change of strain, and so on The increase of the pore water pressure results in reduction of the effective stress, which is a direct indication of soil liquefaction. Time history of the pore water pressure and the mean effective stress of element 681 and element 865 are plotted in Figures 21 and 22, respectively. Element 681 and element 865 are located at the center of the liquefied soil layer, as shown in Figure 18. It can be seen that the excess pore water pressure generates rapidly from about 30 seconds, the first main shock, and reaches maximum even before the second main shock. The mean effective stress experienced rapid decrease as well, corresponding to the time when a large amount of the excess

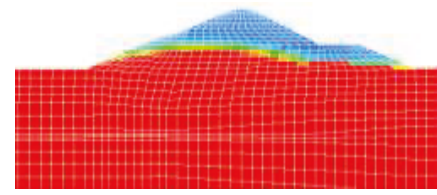

(a) Initial

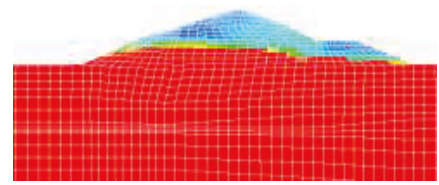

(b) $60 \mathrm{~s}$

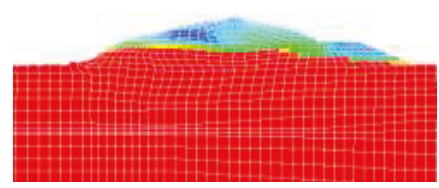

(c) $100 \mathrm{~s}$

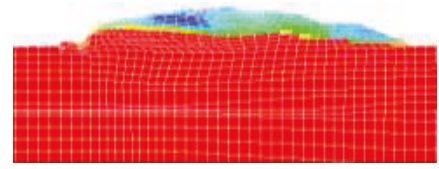

(d) $200 \mathrm{~s}$

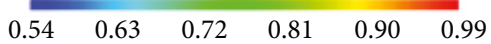

FIGURE 28: Distribution of degree of saturation.

pore water pressure is generated. Therefore, element 681 and element 865 are liquefied after the first main shock.

The distribution of the pore water pressure, the mean effective stress, and the skeleton stress decreasing ratio are shown in Figures 23, 24, and 25, respectively. It can be observed that the excess pore water pressure is generated within the embankment, which leads to the reduction of the mean effective stress to a minimum value of $1.9 \mathrm{kPa}$ at 60 seconds. The mean skeleton stress decreasing ratio (ESDR) is defined by

$$
\operatorname{ESDR}=1-\frac{\sigma_{m}^{\prime}}{\sigma_{m 0}^{\prime}} .
$$

According to Figure 25, the minimum value of ESDR in the embankment is $90 \%$ at 60 seconds, indicating a complete liquefaction after the first mean shock.

Distribution of the accumulative deviatoric plastic/viscoplastic strain (GAMP) is shown in Figure 26. Although GAMP appears to be small at $60 \mathrm{~s}$, the maximum GAMP is in fact $52 \%$. As the simulation continues, a clear shear band was developed along the base of the liquefied soil layer. At the end of the dynamic analysis, the maximum value of GAMP is $224 \%$ that causes large deformation of the embankment.

The distribution of the suction and distribution of the degree of saturation are shown in Figures 27 and 28, 
TABLE 4: Time steps used in consolidation analysis.

\begin{tabular}{lccc}
\hline Time step $\Delta t$ & Sec & Simulation time \\
\hline 0.002 & 210 & 0.06 & 0.002 \\
0.005 & 215 & 0.06 & 0.002 \\
0.02 & 235 & 0.07 & 0.003 \\
0.05 & 285 & 0.08 & 0.003 \\
0.2 & 485 & 0.13 & 0.006 \\
0.5 & 985 & 0.27 & 0.011 \\
1 & 1985 & 0.55 & 0.023 \\
2 & 3985 & 1.11 & 0.046 \\
5 & 8985 & 2.50 & 0.104 \\
10 & 18,985 & 5.27 & 0.220 \\
20 & 38,985 & 10.83 & 0.451 \\
50 & 88,985 & 24.72 & 1.030 \\
100 & 188,985 & 52.50 & 2.187 \\
200 & 388,985 & 108.05 & 4.502 \\
500 & 620,000 & 172.22 & 7.176 \\
\hline
\end{tabular}

respectively. The initial maximum suction is set to be $14.5 \mathrm{kPa}$, as a result of assuming that the initial degree of saturation is 0.6. The maximum value of suction at the end of consolidation is $19.1 \mathrm{kPa}$. Therefore, in this analysis, the change of suction is not significant. It is observed that during the shaking, the unsaturated soil on the land side of the embankment increases whereas that on the river side decreases. This is mainly due to the deformation of the embankment. In addition, the increase in degree of saturation is also due to the shorter drainage length on the river side of the embankment that was caused by large settlement of the embankment.

4.4. Reconsolidation Behavior. Although the dynamic behavior and the reconsolidation behavior of liquefied river embankment are discussed separately, the reconsolidation analysis is a continuation of the dynamic simulation by setting ground acceleration to zero. Therefore, material parameters, boundary conditions, and numerical conditions remain unchanged from the dynamic analysis. Note that the reconsolidation analysis starts at 4000 seconds which is the same as the onset time in 1-D analysis, in order to retain the stiff low-rigidity zone of liquefied soil as well as to avoid any numerical instability. The time step for dynamic analysis was 0.002 second, which is too small for consolidation analysis. Hence, time steps are gradually increased during consolidation analysis. The time history of the time steps is shown in Table 4.

The results from reconsolidation analysis are shown in Figures $29,30,31,32,33,34,35$, and 36 . The same elements, element 681 and element 865 , are chosen for illustrating the pore water pressure dissipation during reconsolidation. From Figure 29, it could be observed that the excess pore water pressure dissipates immediately after the beginning of reconsolidation, from 4000 second. Meanwhile, the mean effective stress is effective in recovering as excess pore water pressure dissipates, as shown in Figure 30. The excess pore water

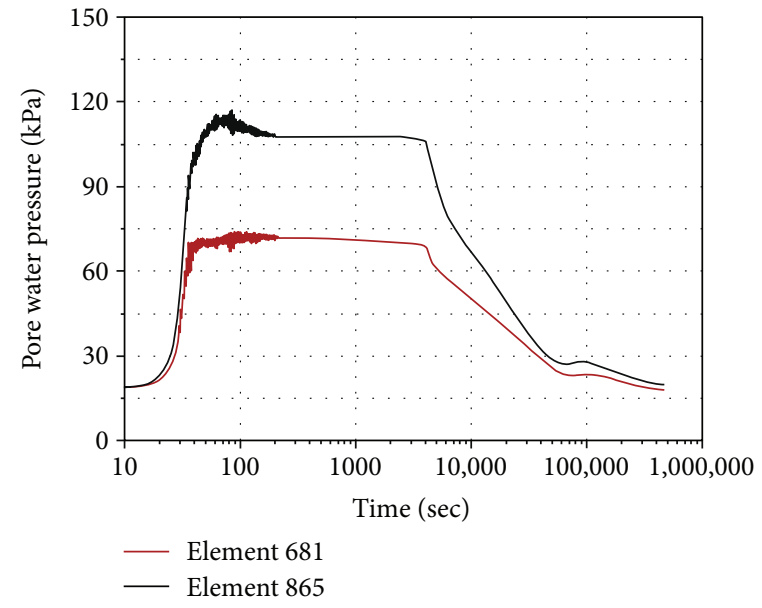

FIgURe 29: Dissipation of excess pore water pressure for element 681 and element 865 during consolidation.

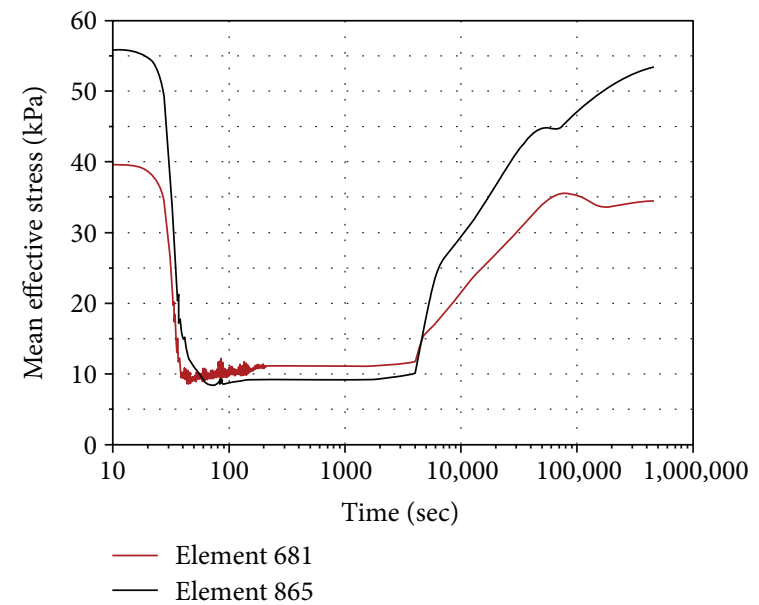

Figure 30: Recovery of mean effective stress for element 681 and element 865 during consolidation.

pressure is fully dissipated after approximately 400,000 seconds (110 hours). Fluctuation of pore water pressure and mean effective stress are found at about 60,000 seconds. One shall note that unlike one-dimensional analysis, the behavior of the elements is affected by global behavior of the river embankment and the interaction with other soil layers. The stress paths of element 681 and element 865 during dynamic and reconsolidation analysis are shown in Figure 31. It could be observed that the mean effective stresses for both elements are not completely reduced to zero after liquefaction. This is due to the combination effect by the nonassociativity parameter $C_{n s}$ and the nonlinear kinematic hardening parameter $y_{m}^{*}$.

Figures 32,33, and 34 depict the change of distribution of pore water pressure, mean effective stress, and ESDR. The distribution of pore water pressure was smooth at 11 hours, but the excess pore water pressure was not fully dissipated. A full dissipation can be obtained after 110 hours. The distribution of ESDR also shows that the mean effective stress is effectively recovered at 110 hours. It was also found that the 


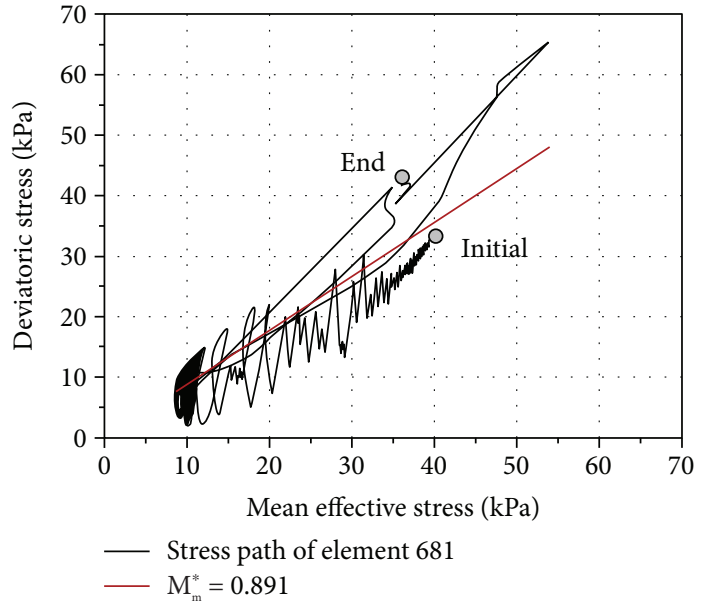

(a) Element 681

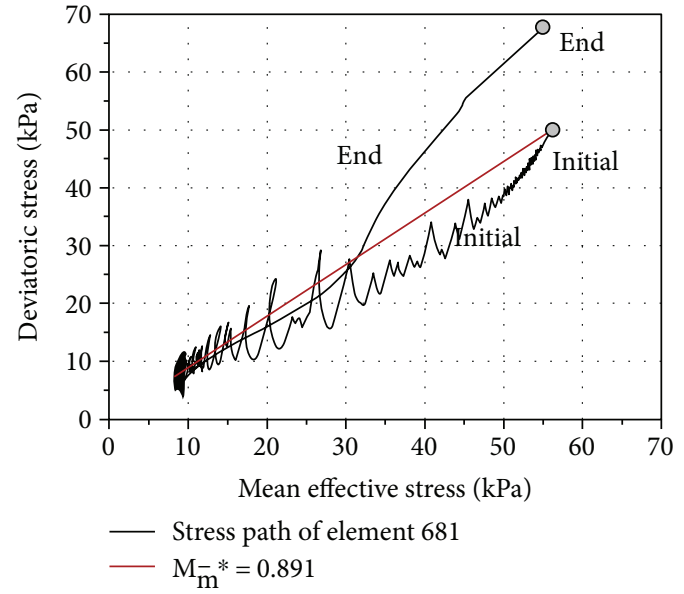

(b) Element 865

Figure 31: Stress paths for dynamic and reconsolidation analysis.

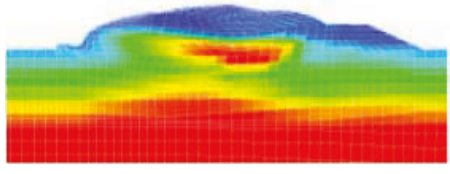

(a) $200 \mathrm{~s}$

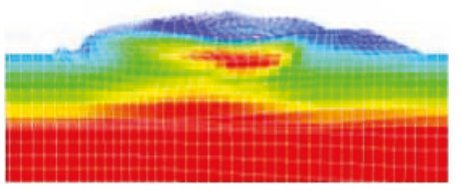

(b) $4,000 \mathrm{~s}$ (1.1 hours)

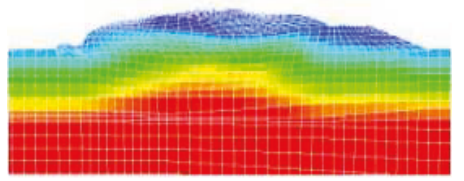

(c) $40,000 \mathrm{~s}$ (11 hours)

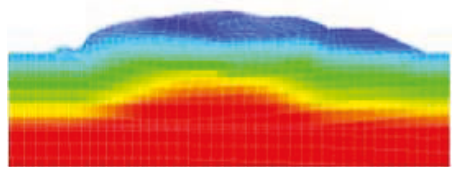

(d) 400,000 s (110 hours)

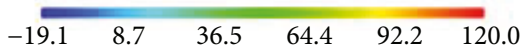

FIGURE 32: Distribution of pore water pressure during reconsolidation (unit: $\mathrm{kPa}$ ).

consolidation analysis has almost no effect on the distribution of suction and degree of water saturation.

As mentioned earlier, soil stiffness was described by the elastic shear modulus $G^{E}$ in (8). Rapid stiffness recovery occurred almost immediately after the onset of reconsolidation, as shown in Figure 35. Note that the stiffness would

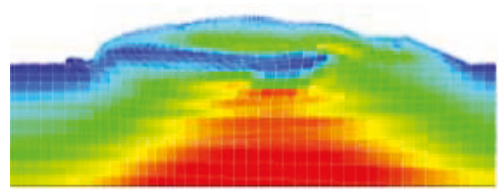

(a) $200 \mathrm{~s}$

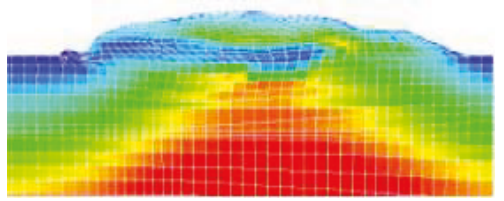

(b) $4,000 \mathrm{~s}$ (1.1 hours)

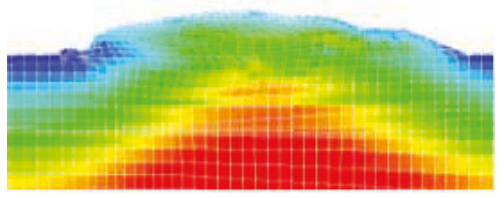

(c) $40,000 \mathrm{~s}$ (11 hours)

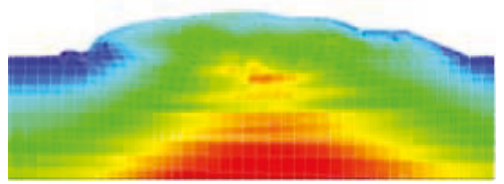

(d) 400,000 s (110 hours)

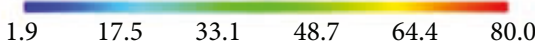

Figure 33: Distribution of mean effective stress during reconsolidation (unit: $\mathrm{kPa}$ ).

not recover until the occurrence of volumetric compression during reconsolidation. In addition, the softening effect due to the increase in accumulative deviatoric strain is seized during reconsolidation. The rate of stiffness recovery is 


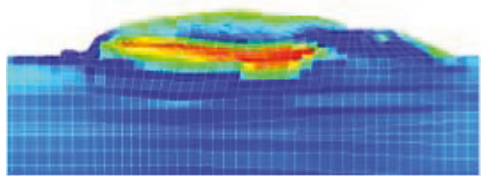

(a) $200 \mathrm{~s}$

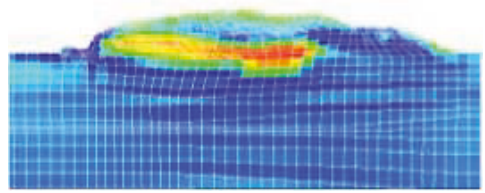

(b) $4,000 \mathrm{~s}$ (1.1 hours)

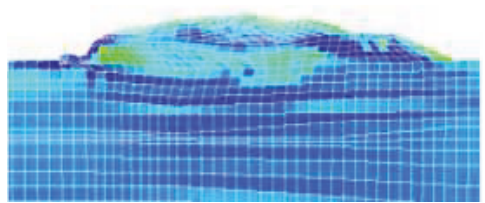

(c) $40,000 \mathrm{~s}$ (11 hours)

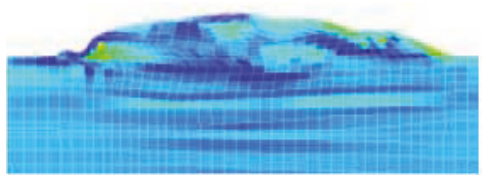

(d) $400,000 \mathrm{~s}$ (110 hours)

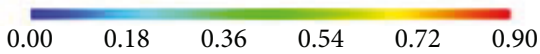

FIGURE 34: Distribution of mean skeleton stress decreasing ratio (ESDR) during reconsolidation.

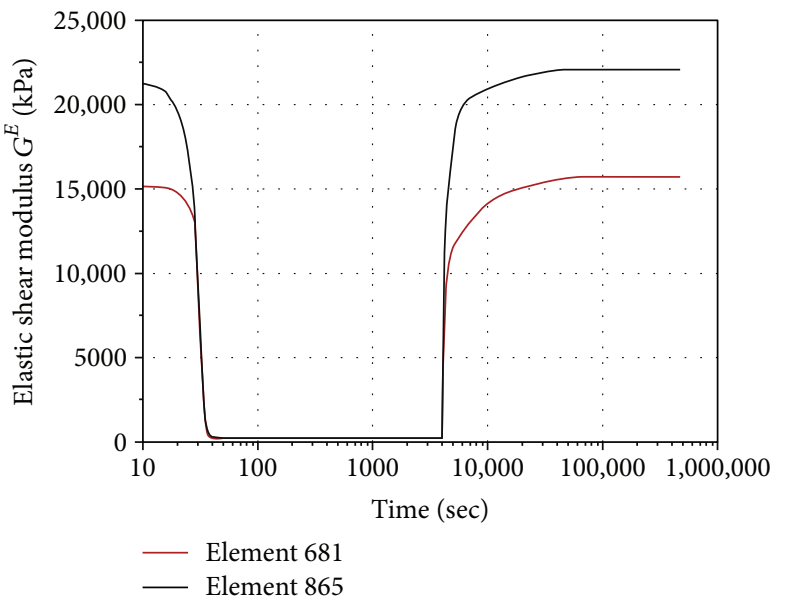

FIGURE 35: Recovery of elastic shear modulus for element 681 and element 865 during consolidation.

mainly governed by the input parameter $C_{c f}$, which should be chosen depending on experimental results. In this analysis, $C_{c f}$ is set to be 2000 .

Vertical displacement during dynamic and reconsolidation analysis is shown in Figure 36. It can be seen that the

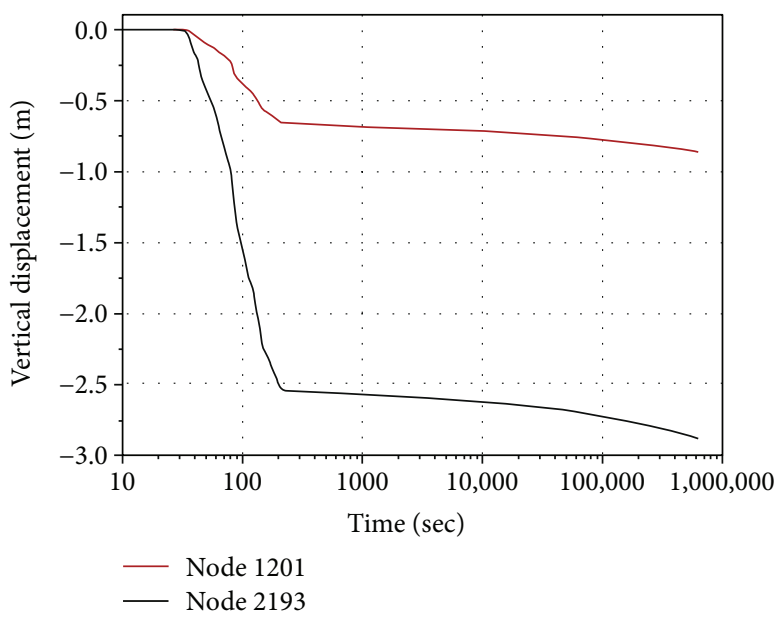

Figure 36: Time history of vertical displacement for 110 hours.

vertical displacement rate decreased drastically after $200 \mathrm{sec}-$ onds when the shaking was stopped. Consolidation settlement continues slowly for node 1201 and node 2193, at almost the same rate. The consolidation settlement was not only contributed to by the embankment fill but also by the foundation clay.

\section{Conclusions}

In the present study, first, an extended cyclic elastoplastic constitutive model [14] was introduced into a three-phase coupled finite element program COMVI2D-DY. This model is then modified by incorporating volumetric compression hardening during reconsolidation. The cyclicreconsolidation behavior of the extended model is studied and examined by one-dimensional analysis. It can be concluded that stiffness recovery during consolidation is effectively reflected on the elastic and plastic shear stiffness, which results in significant reduction of the consolidation settlement. Second, a severely damaged river embankment along the Naruse River in Tohoku District during the 2011 off-the-Pacific-Coast Tohoku earthquake is simulated to validate the numerical method of COMVI2D-DY incorporating the behaviors of the cyclic elastoviscoplastic model and the extended cyclic elastoplastic model. The validation exercise is based upon comparing the monitored deformation pattern of the river embankment with that from simulation. From the simulation results, it could be concluded that the numerical method is able to reproduce the key characteristics of the actual damaged pattern.

\section{Data Availability}

The data used to support the findings of this study are available from the corresponding author upon request.

\section{Conflicts of Interest}

The authors declare that there is no conflict of interest regarding the publication of this paper. 


\section{Acknowledgments}

The authors acknowledge the National Research Institute for Earth Science and Disaster Prevention (NIED) for providing KiK-net strong-motion data.

\section{References}

[1] Y. Sasaki, I. Towhata, K. Miyamoto et al., "Reconnaissance report on damage in and around river levees caused by the 2011 off the Pacific coast of Tohoku earthquake," Soils and Foundations, vol. 52, no. 5, pp. 1016-1032, 2012.

[2] Tohoku Regional Development Bureau of Ministry of Land, Infrastructure, Transport and Tourism, Report of Restoration of River Embankment along Kitakami River and etc, 2011.

[3] F. Oka, P. Tsai, S. Kimoto, and R. Kato, "Damage patterns of river embankments due to the 2011 off the Pacific coast of Tohoku earthquake and a numerical modeling of the deformation of river embankments with a clayey subsoil layer," Soils and Foundations, vol. 52, no. 5, pp. 890-909, 2012.

[4] M. Okamura and S. Hayashi, "Damage to river levees by the 2011 off the Pacific coast Tohoku earthquake and prediction of liquefaction in levees," in Geotechnics for Catastrophic Flooding Events, pp. 57-67, 2014.

[5] A. Yamaguchi, T. Mori, M. Kazama, and N. Yoshida, "Liquefaction in Tohoku district during the 2011 off the Pacific coast of Tohoku earthquake," Soils and Foundations, vol. 52, no. 5, pp. 811-829, 2012.

[6] R. de Boer, Theory of Porous Media, Springer, 2000.

[7] B. A. Schrefler, "Mechanics and thermodynamics of saturated/ unsaturated porous materials and quantitative solutions," Applied Mechanics Reviews, vol. 55, no. 4, pp. 351-388, 2002.

[8] Y. Huang, A. Yashima, K. Sawada, and F. Zhang, "A case study of seismic response of earth embankment foundation on liquefiable soils," Journal of Central South University of Technology, vol. 16, no. 6, pp. 994-1000, 2009.

[9] Y. Okochi, S. Sreng, M. Matsumoto, H. Miki, M. Tsuda, and H. Ito, "Numerical simulation of centrifuge model tests on embankment with a new liquefaction countermeasure by ground improvement considering constraint effect," in 6th International Conference on Earthquake Geotechnical Engineering, Christchurch, New Zealand, November 2015.

[10] R. Uzuoka and K. Semba, "Numerical analysis of liquefaction in a river levee on soft cohesive ground," Journal of Disaster Research, vol. 7, no. 6, pp. 711-717, 2012.

[11] T. Yoshikawa, T. Noda, T. Kodaka, and T. Takaine, "Analysis of the effect of groundwater level on the seismic behavior of an unsaturated embankment on clayey ground," Soil Dynamics and Earthquake Engineering, vol. 85, pp. 217-230, 2016.

[12] H. Sadeghi, Dynamic analysis of river embankments during earthquakes based on finite deformation theory considering liquefaction, Kyoto University, 2014, Doctoral dissertation.

[13] B. Shahbodagh Khan, Large deformation dynamic analysis method for partially saturated elasto-viscoplastic soils, Kyoto University, 2011, Doctoral dissertation.

[14] F. Oka and S. Kimoto, "Cyclic elastoplastic constitutive model for soils based on non-linear kinematical hardening rule with volumetric and deviatoric kinematical parameters," in Bifurcation and Degradation of Geomaterials with Engineering Applications, IWBDG 2017, E. Papamichos, P. Papanastasiou, E.
Pasternak, and A. Dyskin, Eds., pp. 81-87, Springer Series in Geomechanics and Geoengineering, 2017.

[15] F. Oka and S. Kimoto, Computational Modeling of Multi-Phase Gematerials, CRC Press, Taylor \& Francis group, 2012.

[16] F. Oka and S. Kimoto, "A cyclic elastoplastic constitutive model and effect of non-associativity on the response of liquefiable sandy soils," Acta Geotechnica, pp. 1-15, 2018.

[17] R. Kato, F. Oka, and S. Kimoto, "A numerical simulation of seismic behavior of highway embankments considering seepage flow, computer methods and recent advances in geomechanics," in Proc. of the 14th Int. Conf. Of International Association for Computer Methods and Recent Advances in Geomechanics, pp. 755-760, Kyoto, Japan, 2014.

[18] D. Gallipoli, A. Gens, G. Chen, and F. D’Onza, “Modelling unsaturated soil behaviour during normal consolidation and at critical state," Computers and Geotechnics, vol. 35, no. 6, pp. 825-834, 2008.

[19] C. Jommi, "Remarks on the constitutive modelling of unsaturated soils," Experimental Evidence and Theoretical Approaches in Unsaturated Soil, pp. 139-153, 2000.

[20] L. Laloui and M. Nuth, "On the use of the generalised effective stress in the constitutive modelling of unsaturated soils," Computers and Geotechnics, vol. 36, no. 1-2, pp. 20-23, 2009.

[21] F. Oka, T. Kodaka, S. Kimoto, Y. S. Kim, and N. Yamasaki, An Elasto-Viscoplastic Model and Multiphase Coupled FE Analysis for Unsaturated Soil. Unsaturated Soils 2006, ASCE, 2006.

[22] S. Kimoto, B. Shahbodagh Khan, M. Mirjalili, and F. Oka, "Cyclic elastoviscoplastic constitutive model for clay considering nonlinear kinematic hardening rules and structural degradation," International Journal of Geomechanics, vol. 15, no. 5, article A4014005, 2015.

[23] M. T. van Genuchten, "A closed-form equation for predicting the hydraulic conductivity of unsaturated soils1," Soil Science Society of America Journal, vol. 44, no. 5, pp. 892-899, 1980.

[24] F. Oka, A. Yashima, A. Tateishi, Y. Taguchi, and A. Yamashita, "A cyclic elasto-plastic constitutive model for sand considering a plastic-strain dependence of the shear modulus," Géotechnique, vol. 49, no. 5, pp. 661-680, 1999.

[25] National Research Institute for Earth Science and Disasters Resilience (NIED), Ground Motion Data MYGHO6 (-80m) at Tajiri Station, Miyagi Prefecture, 2011.

[26] B. Ye, H. Yokawa, T. Kondo, A. Yashima, F. Zhang, and N. Yamada, "Investigation on stiffness recovery of liquefied sandy ground after liquefaction using shaking-table tests," in Soil and Rock Behavior and Modeling, 2006.

[27] National Institute for Land and Infrastructure Management, "Technical Report, Prompt Report on Damage of Civil Structures Caused by the 2011 Great East Japan Earthquake (NILIM and PWRI)," 2011, Chapter 6.

[28] Geological Survey of Japan, Online Geological Map of Japan, 2017, https://gbank.gsj.jp/geonavi/geonavi.php\#8,38. $764,140.213$.

[29] R. F. Carsel and R. S. Parrish, "Developing joint probability distributions of soil water retention characteristics," Water Resources Research, vol. 24, no. 5, pp. 755-769, 1988. 

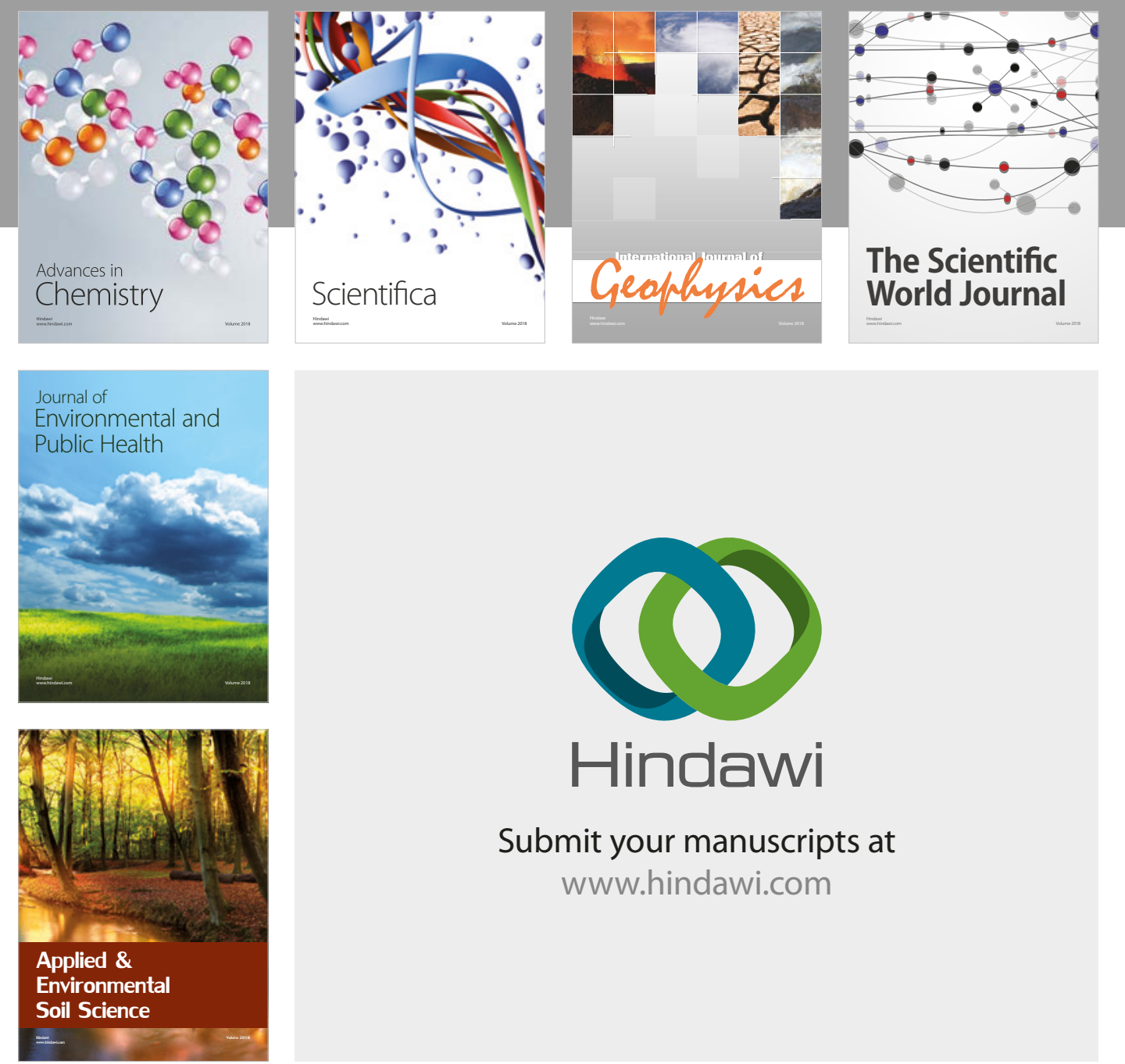

The Scientific

\section{World Journal}
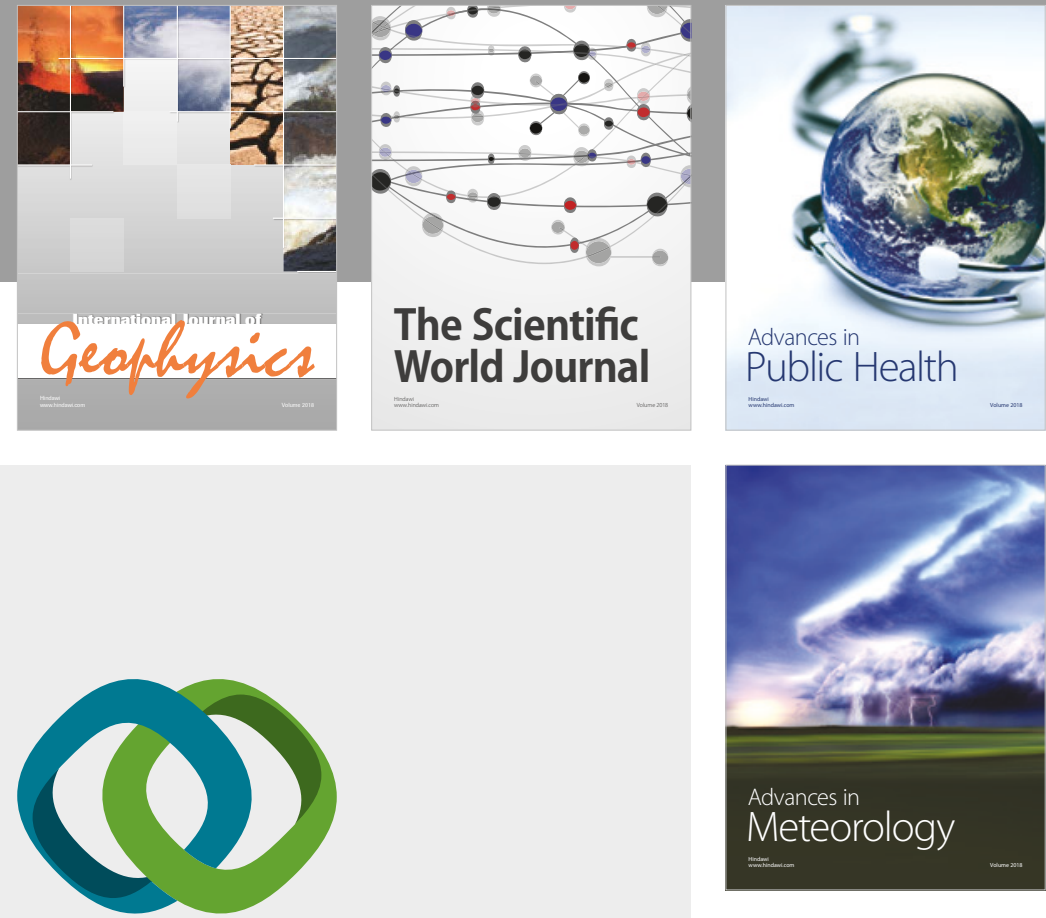

Advan

Public Health

\section{Hindawi}

Submit your manuscripts at

www.hindawi.com
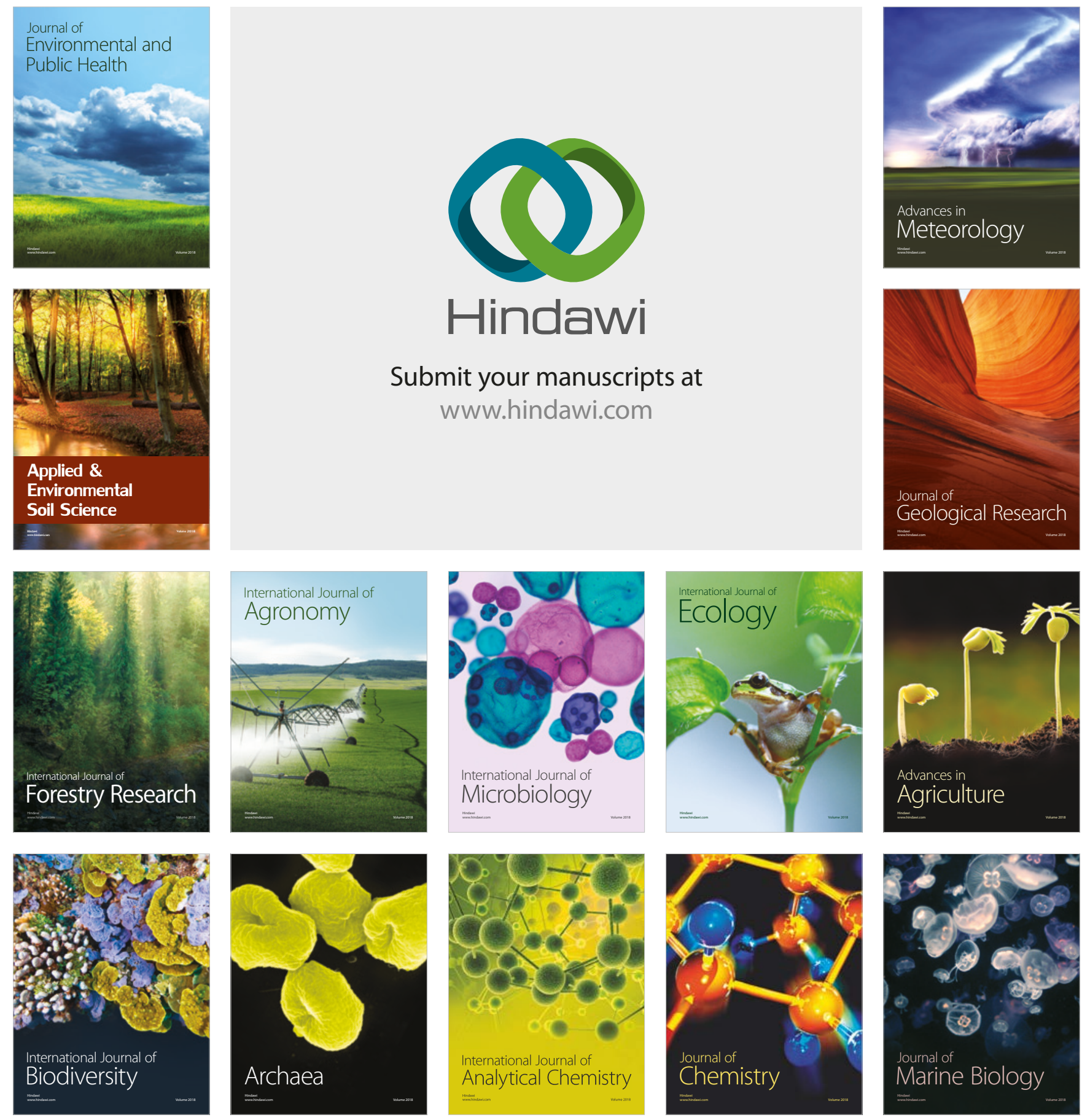